\title{
Astrocyte Glutamine Synthetase: Importance in Hyperammonemic Syndromes and Potential Target for Therapy
}

\author{
Saul W. Brusilow, ${ }^{*}$ Raymond C. Koehler, ${ }^{\dagger}$ Richard J. Traystman, ${ }^{\ddagger}$ and Arthur J. L. Cooper ${ }^{\S}$ \\ *Department of Pediatrics and ${ }^{\dagger}$ Department of Anesthesiology and Critical Care Medicine, The Johns Hopkins University School \\ of Medicine, Baltimore, MD 21287; ${ }^{\ddagger}$ Office of the Vice Chancellor for Research, Department of Pharmacology, University of \\ Colorado Denver, Aurora, CO 80045; ${ }^{\S}$ Department of Biochemistry and Molecular Biology, New York Medical College,
} Valhalla, NY 10595

\begin{abstract}
Summary: Many theories have been advanced to explain the encephalopathy associated with chronic liver disease and with the less common acute form. A major factor contributing to hepatic encephalopathy is hyperammonemia resulting from portacaval shunting and/or liver damage. However, an increasing number of causes of hyperammonemic encephalopathy have been discovered that present with the same clinical and laboratory features found in acute liver failure, but without liver failure. Here, we critically review the physiology, pathology, and biochemistry of ammonia (i.e., $\mathrm{NH}_{3}$ plus $\mathrm{NH}_{4}{ }^{+}$) and show how these elements interact to constitute a syndrome that clinicians refer to as hyperammonemic encephalopathy (i.e., acute liver failure, fulminant hepatic failure, chronic liver disease). Included will be a brief history of the status of ammonia and the centrality of the astrocyte in brain nitrogen metabolism. Ammonia is normally detoxified in the liver and extrahepatic tissues by
\end{abstract}

conversion to urea and glutamine, respectively. In the brain, glutamine synthesis is largely confined to astrocytes, and it is generally accepted that in hyperammonemia excess glutamine compromises astrocyte morphology and function. Mechanisms postulated to account for this toxicity will be examined with emphasis on the osmotic effects of excess glutamine (the osmotic gliopathy theory). Because hyperammonemia causes osmotic stress and encephalopathy in patients with normal or abnormal liver function alike, the term "hyperammonemic encephalopathy" can be broadly applied to encephalopathy resulting from liver disease and from various other diseases that produce hyperammonemia. Finally, the possibility that a brain glutamine synthetase inhibitor may be of therapeutic benefit, especially in the acute form of liver disease, is discussed. Key Words: Astrocyte swelling, cerebral edema, hepatic encephalopathy, hyperammonemia, glutamine synthetase.

\section{HISTORICAL PERSPECTIVES}

In the early 1930s, van Caulaert and Deviller ${ }^{1}$ and van Caulaert et al. $^{2}$ reported what may have been the first description of ammonia neurotoxicity in patients with liver disease. A few years later, Kirk ${ }^{3}$ published a detailed study of nitrogen metabolism in control subjects and in patients with a variety of liver diseases. In the current review, hepatic encephalopathy is broadly categorized by the nature of the hepatic abnormality (i.e., acute liver failure, portal systemic shunts, and hepatocellular disease ${ }^{4}$ ). Despite the limitations by today's stan-

Address correspondence and reprint requests to: Saul W. Brusilow, M.D., The Johns Hopkins University School of Medicine, 4615 North Park Ave., \#701, Chevy Chase, MD 20815; E-mail: sbrusilo@jhmi. edu; or Arthur J. L. Cooper Ph.D., D.Sc., Department of Biochemistry and Molecular Biology, New York Medical College, Valhalla, NY 10595. E-mail: arthur_cooper@nymc.edu. dards of the analytical methods available in the mid1930s, Kirk was able to establish the basics of hepatic nitrogen metabolism in man as follows: 1) the portal vein is the major source of ammonia arising from the "putrefaction" of nitrogenous substances in the gut; 2) the liver is the major organ for removal of portal vein ammonia and for metabolism of amino acids; 3) most, if not all, urea is synthesized in the liver; and 4) the concentration of blood ammonia in normal subjects and in patients with liver disease is relatively low (approximately 15 and 30 $\mu \mathrm{mol} / \mathrm{L}$, respectively). ${ }^{3}$

Throughout the last century the encephalopathy associated with liver disease was attributed to many factors. The role of ammonia in the encephalopathy associated with liver disease was controversial, despite the seminal studies of van Caulaert, Kirk, ${ }^{3}$ and later studies by Gabuzda et al., ${ }^{5}$ and Phillips et al., ${ }^{6}$ in the 1950s, who showed a relationship between ammonia administration 
and neurological symptoms in patients with liver disease. Many considered ammonia to be the most important factor with the reservation that there were other "liver factors" that contributed to the neurological picture and accounted for the occasional apparent absence of hyperammonemia. At the beginning of the 21 st century, most, but not all, investigators now believe that hyperammonemia is a major factor in the encephalopathy associated with liver disease, but as documented, as follows, the relationship between blood ammonia and neurological dysfunction is not simple.

Urea cycle disorders were discovered by the late 1970s and described with sufficient clarity to prompt $\mathrm{Shih}^{7}$ to recognize that the clinical picture, biochemistry, and pathology of the encephalopathy found in urea cycle disorders and acute liver failure were identical. She perspicaciously observed: "The importance of ammonia in the pathogenesis of hepatic encephalopathy ... has long been controversial but not until the discovery of congenital hyperammonemia syndromes was the role of ammonia toxicity fully recognized." ${ }^{7}$ Her observation can now be extended to include other nonhepatic settings in which hyperammonemic encephalopathy is found (e.g., idiopathic hyperammonemic syndrome after immunosuppression or cytotoxic therapy, ${ }^{8,9}$ ureolysis in stagnant urine and urinary tract infections, ${ }^{10,11}$ valproate therapy, ${ }^{12,13}$ and essential amino acid total parenteral nutrition $^{14}$ ). Despite Shih's ${ }^{7}$ telling observation, the role of ammonia in liver disease remains controversial among some investigators ${ }^{15}$ and may even be omitted altogether from discussions of acute liver failure, ${ }^{16}$ notwithstanding an estimate that the incidence of hyperammonemia is $90 \%$ in patients with liver failure. ${ }^{17,18}$ Nevertheless, the majority of workers in the field now recognize that excess uptake of ammonia by the brain is a contributing factor to hepatic encephalopathy. For some perspectives on liver disease and the neurotoxicity of ammonia for the last half century, see the various references for example. $^{17-32}$

\section{PLASMA AMMONIA}

Measurement of blood/plasma ammonia levels is challenging because of inherently low concentrations, the risk of environmental contamination, and the possibility of ammonia formation from endogenous metabolites in stored samples. Apart from blood drawn from an indwelling catheter, questions still remain regarding, for example, optimal sample processing, normal reference values for arterial and venous samples, and tourniquet effects. ${ }^{32}$ For example, in our experience, the application of a tourniquet has a small, but highly significant effect $(p<0.03$ [males]; $p<0.003$ [females]; $p<0.00001$ [combined]; paired $t$ test) on plasma ammonia levels. Ammonia levels (mean \pm standard error of the mean) in plasma derived from blood drawn from a vein in one arm in normal adult males $(n=4)$ and females $(n=6)$ were $17.3 \pm 1.5$ and $19.3 \pm 1.0 \mu \mathrm{M}$, respectively. The corresponding values in plasma derived from blood drawn from a vein in the contralateral arm with the tourniquet were $24.7 \pm 1.0$ and $25.3 \pm 2.1 \mu \mathrm{M}$, respectively.

Clinicians should be aware of The Medical Device Amendment of 1976 to the Food and Drug (FDA) Cosmetic Act, which was designated to regulate the safety and effectiveness of in vitro diagnostic devices through the Center for Devices and Radiologic Health. At that time, the Dupont Automatic Clinical Analyzer (Glasgow, $\mathrm{DE}$ ), which was already on the market (but is no longer manufactured), was approved by the FDA without scrutiny as class 1 , the weakest regulatory oversight. All ammonia-measuring devices marketed after the 1976 amendment were also rated as class 1 without testing, provided they were found to be substantially equivalent to the pre-1976 instrument, which itself is untested. As much as drugs are approved for specific diseases by the FDA, it is the same for medical devices. Ammonia measurements are now approved by the Center for Devices and Radiologic Health for "severe liver disorders such as cirrhosis, hepatitis, and Reye's Syndrome." All other uses (e.g., in urea cycle disorders or idiopathic hyperammonemic syndrome) would be "off-label." As with offlabel drugs, off-label devices may be helpful, but physicians should be aware of limitations imposed by the weak regulatory status. For a discussion of methods available for measurement of plasma and blood ammonia, see Brusilow. ${ }^{33}$

\section{CLINICAL FINDINGS}

Patients with hyperammonemia due to, for example, acute liver failure, urea cycle disorders, idiopathic hyperammonemic syndrome, or ureolysis of stagnant urine are alike clinically, biochemically, physiologically, and pathologically. Patients characteristically exhibit a progressive global encephalopathy commencing with hyperventilation, irritability, and/or lethargy, progressing to confusion, combativeness and somnolence, failure to respond to external stimuli, decorticate and decerebrate posturing, cerebral edema and increased intracranial pressure (ICP), hemodynamic instability, and respiratory arrest. In the most severe cases, deep coma and eventual death ensue. For example, see selected references. ${ }^{21,34-45}$ Acute liver failure with cerebral edema and high ICP has a high mortality rate. ${ }^{44}$

Laboratory findings, in addition to hyperammonemia, include an early respiratory alkalosis (perhaps the earliest objective evidence of hyperammonemic encephalopathy, but unfortunately this has often been ignored, even when measured). For example, respiratory alkalosis is regularly observed in children with hyperammonemia 
Table 1. Important Neuropathological Features of Experimental Hyperammonemia (in the Absence of Overt Liver Disease), Hepatic Failure, Hepatic Encephalopathy, and Inborn Errors of the Urea Cycle*

\begin{tabular}{|c|c|c|c|c|}
\hline & Experimental Hyperammonemia & $\begin{array}{l}\text { Acute Liver } \\
\text { Failure }\end{array}$ & Hepatic Encephalopathy & $\begin{array}{l}\text { Inborn Errors of the } \\
\text { Urea Cycle }\end{array}$ \\
\hline Hyperammonemia & + & + & + & + \\
\hline Respiratory alkalosis & + & + & + & + \\
\hline Cerebral glutamine & $\uparrow$ & $\uparrow$ & $\uparrow$ & $\uparrow$ \\
\hline CSF glutamine & $\uparrow$ & $\uparrow$ & $\uparrow$ & $\uparrow$ \\
\hline Cerebral myo-inositol & $\downarrow$ & $\downarrow$ & $\downarrow$ & $\downarrow$ \\
\hline Astrocyte swelling & + & + & + & + \\
\hline Cerebral edema & + & + & $\pm^{\dagger}$ & $\pm^{\dagger}$ \\
\hline Encephalopathy & + & + & + & + \\
\hline
\end{tabular}

$+=$ occurrence; $\uparrow=$ increase; $\downarrow=$ decrease; CSF $=$ cerebrospinal fluid.

*The table is modified from Brusilow. ${ }^{41}$ For original references, see Brusilow. ${ }^{41}$

The \pm symbol indicates that cerebral edema is usually less pronounced in these two groups compared to that in patients with acute liver failure. However, the increase in astrocyte size in the fixed volume of the skull is consistent with "astrocyte edema. ${ }^{4}$ The summary in the last columns is a composite based on the experience of one of the present authors (SWB) with 545 cases of urea cycle disorders. ${ }^{37}$

due to ornithine transcarbamylase deficiency ${ }^{46}$ In addition, high concentrations of glutamine in plasma and CNS are observed in hyperammonemic syndromes. Lavoie et al. ${ }^{47}$ noted that brain glutamine levels are elevated 2- to 4-fold in autopsied brain samples from patients who died of hepatic encephalopathy. Since the report of Lavoie et al., ${ }^{47}$ which appeared in 1986, noninvasive methods for measuring glutamine in the human brain have been developed. Thus, brain glutamine or glutamine plus glutamate (Glx), can now be measured by magnetic resonance spectroscopy (MRS), and it has been found to be markedly increased in vivo in patients with hyperammonemia. ${ }^{48-54}$ Interestingly, glial alkalization of $0.1 \mathrm{pH}$ unit in portacaval shunted rats and 0.3 to 0.4 $\mathrm{pH}$ unit in severely hyperammonemic rats can be demonstrated in vivo. ${ }^{55,56}$ Alkalization is associated with membrane depolarization and altered $\mathrm{K}^{+}$homeostasis, ${ }^{55,56}$ and this may disrupt the rates of metabolic transformations catalyzed by $\mathrm{pH}$-sensitive enzymes.

Studies with $\left[{ }^{13} \mathrm{~N}\right]$ ammonia have shown that most ammonia enters the brain by nonsaturable diffusion of the free base $\left(\mathrm{NH}_{3}\right)$, although some ammonia can enter the brain as $\mathrm{NH}_{4}{ }^{+32,57-59}$ Note that the $\mathrm{p} K_{\mathrm{a}}$ for ammonia is $\sim 9.2$. Therefore, at physiological $\mathrm{pH}$ values only about $1 \%$ of the ammonia will exist as the free base. However, because the rate of protonation/deprotonation is extremely rapid, diffusion across the blood-brain barrier (BBB) is not limited by rate of proton loss from $\mathrm{NH}_{4}{ }^{+}$. Thus the ratio of ammonia in cerebrospinal fluid (CSF) to that in plasma varies directly with blood $\mathrm{pH}^{60}$ Consequently, the increased blood $\mathrm{pH}$ in respiratory alkalosis in hyperammonemic patients will favor augmented uptake of ammonia from the circulation as a result of higher levels of blood ammonia and a greater proportion in the diffusible $\mathrm{NH}_{3}$ form. Moreover, the permeability-surface area product of the BBB for ammonia has been reported to be increased in patients with liver dis- ease. ${ }^{59}$ However, this finding has been disputed. ${ }^{61}$ Nevertheless, Ahl et al. ${ }^{62}$ were able to detect significant changes of the permeability-surface area product for $\left[{ }^{13} \mathrm{~N}\right]$ ammonia in the thalamus, but not in other brain regions, in hepatic encephalopathy patients. Thus, ammonia uptake into brain in hyperammonemic patients may be increased even when blood ammonia levels are near normal by an increase in blood $\mathrm{pH}$ and possibly by changes in the BBB permeability-surface area product, although this latter possibility is controversial and needs to be resolved. These findings are of importance when considering the effects of metabolic trapping of ammonia in the brain. Apart from the expected cerebral edema, swollen astrocytes are the only brain pathology noted; other brain elements seem to be normal or near normal (Table 1).

The previously mentioned clinical and laboratory findings, which are characteristic of acute life-threatening disease, can be reliably reproduced in intact animals by any method that produces hyperammonemia (e.g., administration of ammonium salts, liver failure induced by hepatotoxins, portal-systemic shunts, urease administration). ${ }^{36,60,63-67} \mathrm{We}$ are unaware of other techniques or substances that can elicit the same responses in the absence of hyperammonemia.

A consistent feature of hyperammonemia, as previously noted, is increased brain glutamine, which leads to complex pathophysiological and neurotoxic responses. As discussed by Pasantes-Morales and Franco, ${ }^{68}$ astrocyte swelling and cerebral edema in acute liver failure seems to be related to several potential mechanisms initiated by glutamine accumulation. Factors discussed in the literature as possibly contributing to hyperammonemic encephalopathy, and summarized by Pasantes-Morales and Franco, ${ }^{68}$ include glutamine acting as an idiogenic osmole, dysregulation of $\mathrm{K}^{+}$homeostasis, altered oxidative metabolism, lactate production, free radical generation, and induction of the mitochondrial perme- 
ability transition (MPT). These factors will be evaluated in a later section. In addition to acute liver failure, there is a much larger group of patients with chronic liver disease that presents with milder hepatocellular damage or portal-systemic shunting with episodic, nonprogressive cognitive and neuropsychiatric problems, but has the same (or very similar) brain pathology as the acute type ${ }^{4}$ (Table 1). Astrocyte dysfunction secondary to glutamine accumulation and its associated effects are likely responsible for the milder symptoms. Although pronounced cerebral edema is infrequent in these patients, some degree of cerebral edema is often observed. In chronic liver disease, we suggest that swollen astrocytes representing an expanded compartment in a confined space produce a pathophysiological effect equivalent to that of the more pronounced cerebral edema of acute liver disease patients. ${ }^{4}$

\section{CEREBRAL AMMONIA METABOLISM}

Because cerebral ammonia metabolism is central to understanding hyperammonemia-induced encephalopathy, a brief review is given here. A large number of enzymes are capable of generating ammonia in the brain. ${ }^{24}$ However, here we are mostly concerned with enzymes that assimilate ammonia in the brain. Two enzymes of relatively high inherent specific activity are theoretically capable of assimilating blood-derived and endogenously produced ammonia in the brain. ${ }^{24}$ These enzymes are glutamate dehydrogenase (Equation [Eq. 1]) and glutamine synthetase (Eq. 2)

$$
\begin{aligned}
& \alpha \text {-Ketoglutarate }+\mathrm{NH}_{3}+\mathrm{NAD}(\mathrm{P}) \mathrm{H} \\
&+\mathrm{H}^{+} \leftrightarrows \text { L-Glutamate }+\mathrm{NAD}^{+}+\mathrm{H}_{2} \mathrm{O}
\end{aligned}
$$

$\mathrm{NH}_{3}+$ L-Glutamate + ATP $\leftrightarrows$ L-Glutamine

$$
+\mathrm{ADP}+\mathrm{P}_{i}
$$

Studies with $\left[{ }^{13} \mathrm{~N}\right]$ ammonia have shown that the overwhelming metabolic fate of blood-borne ammonia entering the brain is incorporation into the amide group of glutamine in both normal ${ }^{57,69}$ and chronically hyperammonemic rats. ${ }^{70}$ Metabolic trapping of blood-derived ammonia in the amide group of glutamine in the normal rat brain is extremely rapid (seconds). ${ }^{57}$ Moreover, when rats were pretreated with $1 \mathrm{mmol} / \mathrm{kg}(180 \mathrm{mg} / \mathrm{kg})$ of L-methionine- $S, R$-sulfoximine (MSO), a potent glutamine synthetase inhibitor, 3 hours before a 10-minute infusion of $\left[{ }^{13} \mathrm{~N}\right]$ ammonia via an indwelling carotid artery, the amount of the administered dose recovered in the brain was much less $(\sim 1 \%)$ than in the control rat brain $(\sim 6 \%) .{ }^{57}$ In the control experiment, $>95 \%$ of the label recovered in the brain was in the amide group of glutamine. However, in MSO-treated rats, of the ${ }^{13} \mathrm{~N}$ label present in the brains of the MSO-treated animals $\sim 41 \%, 10 \%$, and $2.5 \%$ were in glutamine (amide), glu- tamate, and aspartate, respectively. ${ }^{57}$ (The label in aspartate is due to the extremely rapid aspartate aminotransferase reaction.) These findings suggest that not only is glutamine synthetase the major route for removal of ammonia entering the brain from the circulation, but when this enzyme is inhibited there is no other enzyme that can effectively replace glutamine synthetase in trapping blood-derived ammonia in brain tissue.

In a separate experiment, rats were injected with a bolus of $\left[{ }^{13} \mathrm{~N}\right]$ ammonia via the carotid artery and the brains were rapidly frozen 5 seconds later. In control rats, approximately $36 \%$ of the label in the frozen brain sample was in unmetabolized ammonia, approximately $60 \%$ of the label was in the amide group of glutamine, and approximately only $2 \%$ of the label was in glutamate plus aspartate. On the other hand, in MSO-treated rats, approximately $95 \%$ of the label was in unmetabolized ammonia and approximately only $2.5 \%$ was in glutamine, a finding consistent with the $86 \%$ inhibition of brain glutamine synthetase noted in these animals. The MSO treatment was shown to have no effect on the specific activity of brain glutamate dehydrogenase. Nevertheless, in MSO-treated rats, approximately only $2.6 \%$ of the label is recovered in the brain that was in glutamate plus aspartate. In experiments with MSO, the dose administered was subconvulsive. ${ }^{57}$ However, the animals were obtunded. Nevertheless, the data clearly reinforce the conclusion that the glutamine synthetase reaction (Eq. 2), and not the glutamate dehydrogenase reaction (Eq. 1), is the overwhelming route for ammonia assimilation in brains of normal and hyperammonemic rats. Even in MSO-treated rats, which are severely hyperammonemic and in which brain glutamine synthetase activity is greatly decreased, glutamate dehydrogenase in the brain is a very low capacity system for removing ammonia, and it can not adequately compensate as a means of removing excess ammonia. A scheme, based on the previously mentioned $\left[{ }^{13} \mathrm{~N}\right]$ ammonia studies, ${ }^{57,70}$ showing the major routes for ammonia metabolism in the brain is shown in FIG. 1.

The findings with $\left[{ }^{13} \mathrm{~N}\right]$ ammonia are important because they dispel a theory for the mechanism of ammonia neurotoxicity, which is still extensively quoted and can still be found in many textbooks. More than 50 years ago, Bessman and Bessman ${ }^{71}$ theorized that elevated ammonia is neurotoxic because glutamate dehydrogenase-catalyzed reductive amination of $\alpha$-ketoglutarate to glutamate (Eq. 1) is stimulated, resulting in depletion of the tricarboxylic acid (TCA) cycle substrates and decreased ATP reserves. Although the theory was novel in its time and a useful working hypothesis, subsequent work showed that the theory is untenable. The data obtained with $\left[{ }^{13} \mathrm{~N}\right]$ ammonia (described in the previous two paragraphs) are clearly inconsistent with this hypothesis. Moreover, contrary to the Bessman and Bess- 


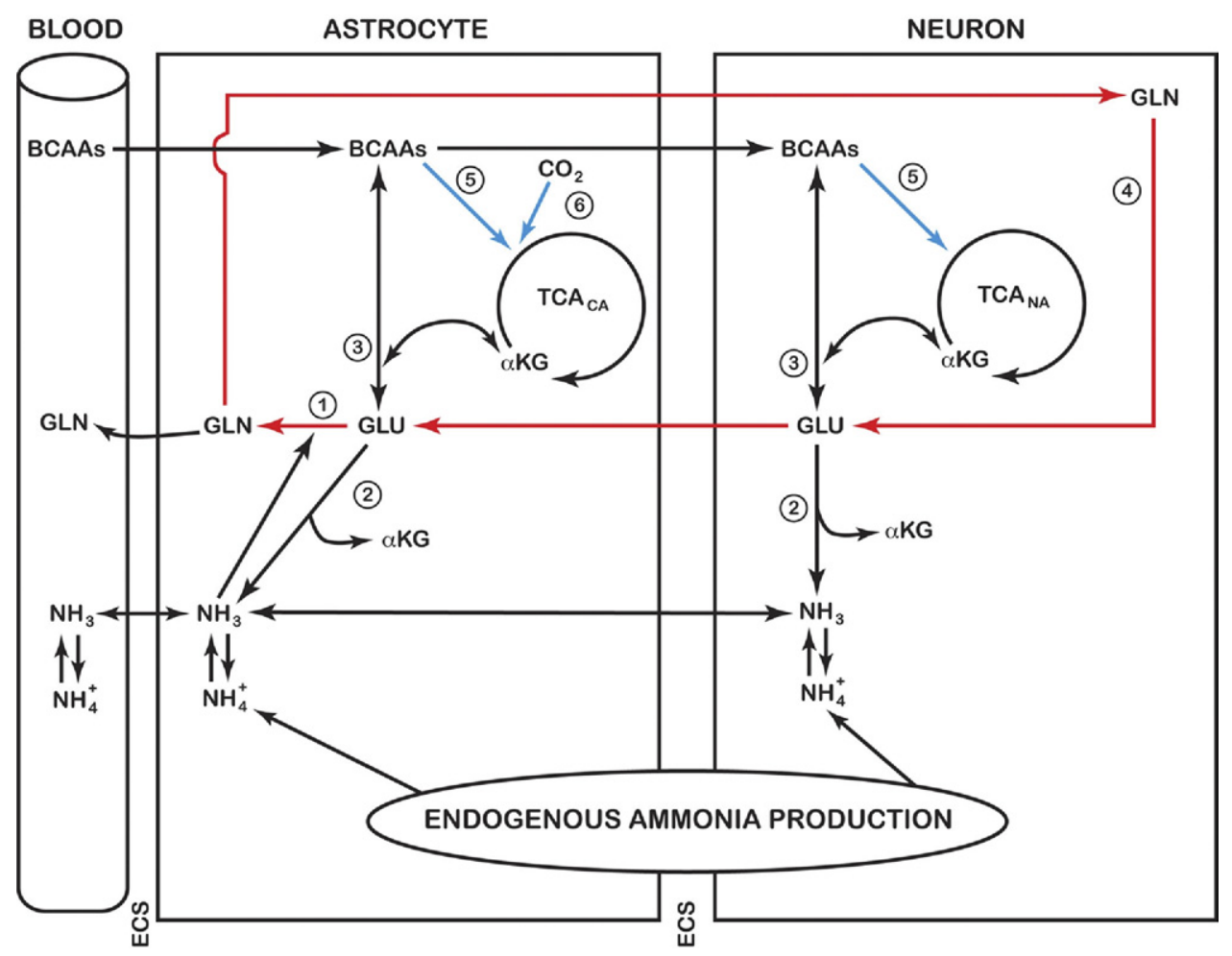

FIG. 1. Cerebral ammonia metabolism. Normal conditions: ammonia enters the brain mostly by diffusion of the free base $\left(\mathrm{NH}_{3}\right)$. This ammonia, and that derived from endogenous reactions, is metabolized primarily via incorporation into the amide position of glutamine in a reaction catalyzed by astrocytic glutamine synthetase (reaction 1). Although the glutamate dehydrogenase reaction is freely reversible, the available evidence suggests that this enzyme is a source of ammonia (reaction 2) rather than a sink for ammonia removal. The glutamate required for glutamine synthesis is derived in part from glutamate released from neurons during neurotransmission. Some of this glutamine may be released to the circulation to maintain nitrogen homeostasis. Another portion may be returned to the neurons, wherein it is converted back to glutamate by the action of glutaminase(s) (reaction 4). The sequence GLU (neurons) $\rightarrow$ GLU (astrocytes) $\rightarrow$ GLN (astrocytes) $\rightarrow$ GLN (neurons) $\rightarrow$ GLU (neurons) is known as the brain glutamine cycle. Hyperammonemia: During hyperammonemia there is a very large increase in brain GLN, but very little net change in $\alpha$-ketoglutarate and glutamate. Thus, there must be a net increase in $\alpha$-amino acid nitrogen. It is proposed that this increased nitrogen is derived from increased flux of 5 - $C$ units through $\alpha$-ketoglutarate-linked transamination reactions, especially those catalyzed by the branched-chain amino acid aminotransferases (reaction 3). During hyperammonemia there must also be a net increase in TCA-cycle-derived 5-C units in glutamine. Evidence suggests that the increased production of $5-\mathrm{C}$ units is due to stimulation of anaplerotic reactions (depicted in blue), particularly $\mathrm{CO}_{2}$ fixation by pyruvate carboxylase $(\rightarrow$, reaction 6$)$ and metabolism of branched-chain amino acids $(\rightarrow$, reaction 5$)$. Hyperammonemia is associated with an increased uptake of neutral amino acids across the blood-brain barrier (BBB). BCAAs = branched-chain amino acids $\mathrm{ECS}=$ extracellular space; $\mathrm{TCA}_{\mathrm{CA}}=\mathrm{TCA}$ cycle in the astrocytic compartment; $\mathrm{TCA}_{\mathrm{NA}}=\mathrm{TCA}$ cycle in the neuronal compartment.

man's ${ }^{71}$ hypothesis, excess ammonia does not significantly affect the concentration of $\alpha$-ketoglutarate in the brain. $^{72,73}$ In chronically hyperammonemic rats challenged with ammonia, brain glutamate is elevated, but only slightly, and only in selected regions. ${ }^{66}$ In addition, glutamate is slightly decreased in the acutely hyperammonemic rat brain. ${ }^{73-75}$ Finally, glutamate levels at autopsy are slightly decreased of prefrontal cortex (by $20 \%$ ), caudate nuclei (by 27\%), and cerebellar vermis (by $17 \%$ ) in patients who died of liver cirrhosis. ${ }^{47}$ However, in all these studies there is a very marked increase in brain glutamine as a result of the persistent hyperammonemia. To emphasize the point again, the evidence is persuasive that during hyperammonemia the overwhelming pathway of ammonia metabolism in the brain is via the glutamine synthetase reaction (Eq. 2) and not via the reductive amination of $\alpha$-ketoglutarate (Eq. 1). These findings are consistent with the hypothesis that increased synthesis of glutamine occurs in the brains of hyperammonemic animals, a central feature of hyperammonemiainduced encephalopathy.

The previously described findings raise an interesting question as follows: What is the origin of the increased 5 -carbon units in glutamine and the increased $\alpha$-amino nitrogen in glutamine in hyperammonemic brain? One possibility is that glutamate uptake into astrocytes from neurons is increased. However, in this case the glutamate pool in neurons will need to be replenished. Uptake of glutamate across the BBB is very low $^{76}$ and presumably can not replenish brain glutamate directed toward glutamine synthesis. The net draining of the 5-carbon units from the TCA cycle toward glutamine is apparently offset by ammonia-stimulated anaplerotic $\mathrm{CO}_{2}$ fixation, ${ }^{77}$ particularly by pyruvate carboxylase ${ }^{78}$ and through provision of the TCA cycle carbon by increased metabolism of branched-chain amino acids. ${ }^{79}$ The brain contains ap- 
preciable branched-chain and aspartate aminotransferase activities, ${ }^{80,81}$ which when coupled with increased uptake of branched-chain amino acids across the $\mathrm{BBB}^{82}$ can maintain brain levels of glutamate via linked transamination reactions ${ }^{83}$ in hyperammonemic animals and simultaneously provide succinyl-CoA to replenish the TCA cycle carbon. This glutamate can then act as a net source of glutamine. Ammonia-induced anaplerosis in the rat brain has been elegantly demonstrated by MRS techniques. $^{84,85}$

Although the TCA cycle-energy depletion theory may be discarded, there is ample evidence that a high ammonia concentration does indeed alter some aspects of cerebral energy metabolism. For example, Hawkins and Jessy $^{67}$ and Hawkins et al. ${ }^{82}$ have shown that hyperammonemia in the rat depressed cerebral glucose utilization. In addition, high ammonia levels inhibit the pyruvate- and $\alpha$-ketoglutarate dehydrogenase complexes, ${ }^{86,87}$ depress the cerebral metabolic rate for glucose, uncouple cerebral blood flow and metabolism in experimental animals, ${ }^{65}$ stimulate glycolysis, ${ }^{88}$ interfere with the malateaspartate shuttle, ${ }^{89}$ and increase brain lactate and the brain lactate/pyruvate ratio. ${ }^{64}$ Increases in cerebral lactate have been observed in patients with acute liver failure. ${ }^{90}$ Despite changes in ammonia-induced energy metabolism, the brain has a remarkable ability to maintain ATP and phosphocreatine homeostasis. ${ }^{64,74}$ Only in endstage ammonia-induced encephalopathy may this safeguard fail in experimental animals. ${ }^{64,74}$ However, ${ }^{31} \mathrm{P}$ MRS has shown that cerebral phosphocreatine is significantly decreased, whereas cerebral ADP and $\mathrm{P}_{\mathrm{i}}$ are significantly increased in patients with chronic liver disease. ${ }^{91}$ The changes correlated with the degree of encephalopathy. On the other hand, cerebral glucose use in the brains of cirrhotic patients, as measured by the $2-\left[{ }^{18} \mathrm{~F}\right]$-fluoro-deoxyglucose technique, showed relative decreased glucose use in the cingulate gyrus, and the frontomedial, frontolateral, and parieto-occipital cortex, but showed relative increased use in the basal ganglia, hippocampus, and cerebellum. ${ }^{92}$

These considerations are important because although the Bessman's TCA depletion theory is invalid, liver disease/hyperammonemia does indeed produce changes in cerebral energy metabolism. However, these changes are not life threatening until end-stage disease.

\section{ASTROCYTES, GLUTAMINE SYNTHESIS AND AMMONIA NEUROTOXICITY}

\section{Morphological effects of excess ammonia on astrocytes}

Unlike most neurodegenerative diseases in which neuronal damage is common, little if any overt damage to neurons occurs during hyperammonemia, except as may occur during prolonged episodes of cerebral edema and increased ICP. The most commonly reported neuropathological feature in both experimental hyperammone$\mathrm{mia}^{55,63,93-101}$ and human hyperammonemia ${ }^{102-104}$ is the presence of enlarged astrocytes containing watery swelling of nuclei and cytosol (type II Alzheimer cells). Excess ammonia also causes morphological abnormalities in astrocytes in culture. ${ }^{105}$ Voorhies et al. ${ }^{98}$ suggested that encephalopathy in acute but limited hyperammonemic syndromes may be completely reversible, because the damage is largely confined to astrocytes. WillardMack et al. ${ }^{101}$ showed that cortical astrocytes in rats were morphologically abnormal 6 hours after a dose of ammonium acetate that produced marked hyperammonemia. The enlarged cortical astrocytes were characterized by 1) decreased electron density of the cytoplasmic matrix in perikaryon, processes, and perivascular end feet; 2) increased circumference of the nuclear membrane; 3 ) increased numbers of mitochondria and rough and smooth endoplasmic reticulum in perikarya and large processes; and (4) less compact bundles of intermediate filaments. ${ }^{101}$ Some of these aberrant changes are illustrated in FIG. 2A.

In the study of Willard-Mack et al., ${ }^{101}$ pentobarbitalanesthetized rats received an intravenous infusion of either sodium or ammonium acetate after intraperitoneal pretreatment with vehicle, MSO $(0.8 \mathrm{mmol} / \mathrm{kg})$ or buthionine sulfoximine (BSO) $(4 \mathrm{mmol} / \mathrm{kg})$, an analogue of MSO that does not inhibit glutamine synthetase. ${ }^{101}$ Pretreatment with MSO, but not $\mathrm{BSO}$, attenuated the decrease in cytoplasmic density and the increase in nuclear circumference (FIG. 2B); most perivascular end feet remained as dense as that which occurred with sodium acetate infusion (controls). However, increased numbers of organelles in expanded perikarya and large processes occurred after MSO treatment with and without ammonium acetate infusion. In separate groups of rats, hyperammonemia produced an increase in cortical tissue water content, which was inhibited by MSO, but not by BSO. ${ }^{101}$ Taken together, these findings strongly suggest that although MSO administration alone causes some morphological changes to rat astrocytes, the compound is strongly protective against acute ammonia-induced swelling of these cells in vivo. Other protective mechanisms of MSO toward astrocytes will be discussed in a later section.

Importantly, Martinez-Hernandez et al. ${ }^{106}$ and Norenberg and Martinez-Hernandez ${ }^{107}$ showed that glutamine synthetase in the brain is located primarily, if not exclusively, in astrocytes. Astrocytic processes surround capillaries (FIG. 2), underlie the ependyma and communicate with all other brain components. The microvascular endothelial cells of the BBB, astrocytes, pericytes, neurons, and basement membrane are now collectively referred to as "the neurovascular unit." Thus, glutamine synthetase is strategically positioned to efficiently metabolize and trap ammonia 


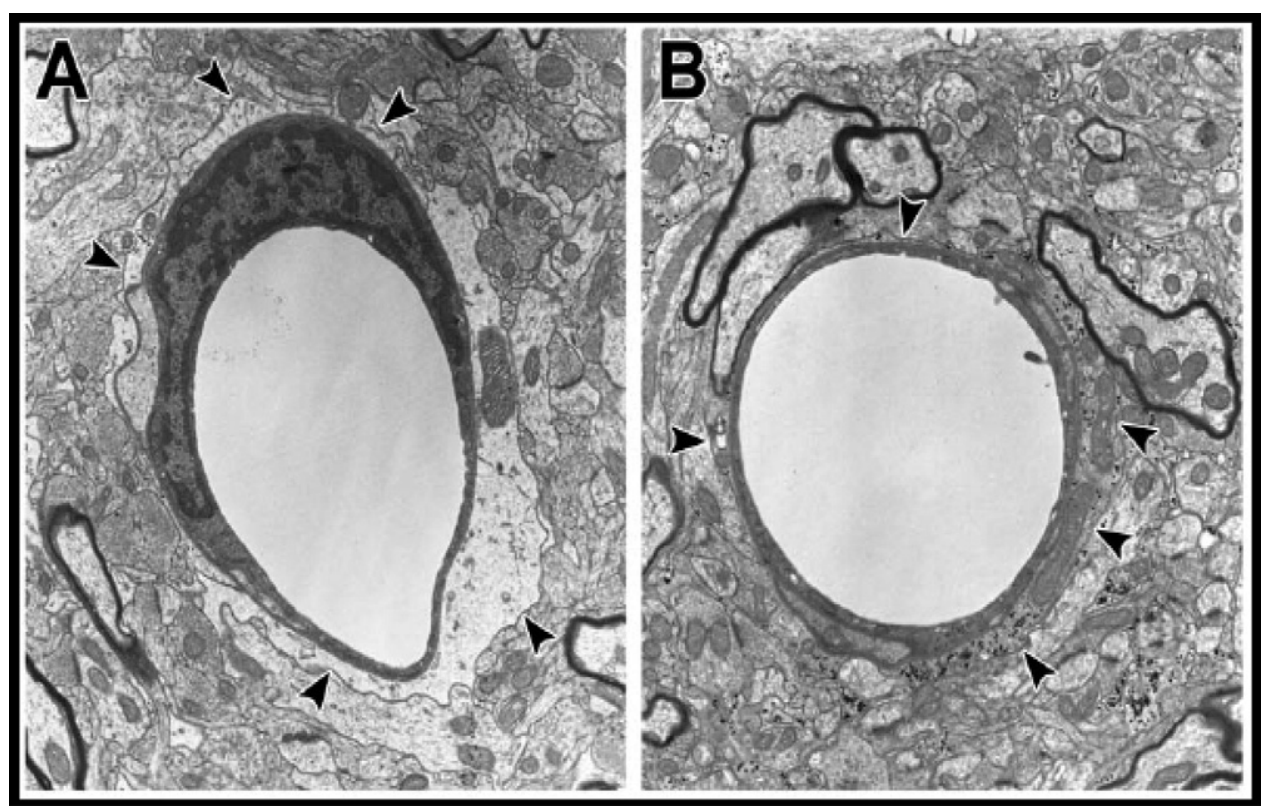

FIG. 2. Electron micrograph of a portion of the cortex of a rat exposed to $6 \mathrm{~h}$ of hyperammonemia without L-methionine-S,Rsulfoximine (MSO) (Panel A) and with MSO (Panel B) pretreatment. The cytoplasm and end feet of an astrocyte surrounding a cross-sectioned capillary are dilated (arrowheads) in the hyperammonemic rat brain (Panel A), but the swelling is prevented by treatment with MSO (Panel B). Scale magnification 10,750-fold. (Modified from Willard-Mack et al., 1996. ${ }^{101}$ )

entering the brain from blood and CSF, as has been shown from tracer studies with $\left[{ }^{13} \mathrm{~N}\right]$ ammonia in the rat..$^{57,69,70}$ Trapping of brain $\left[{ }^{13} \mathrm{~N}\right]$ ammonia in cirrhotic patients has been extensively studied by means of ${ }^{13} \mathrm{~N}$-positron emission tomography (PET).$^{59,62,92,108-111}$ PET analysis of metabolic trapping of blood-borne $\left[{ }^{13} \mathrm{~N}\right]$ ammonia (presumably mostly in the amide nitrogen of glutamine in astrocytes) in the human brain was in the following order: cirrhotics with encephalopathy $>$ cirrhotics without encephalopathy $>$ controls. ${ }^{108}$ The PET studies reinforce the notion that there is increased uptake and trapping of blood-derived ammonia in brains of cirrhotic patients, and, in general, uptake it is more pronounced in the more affected regions of the brain.

Although the PET studies are useful in studying the dynamics of the entry of blood-derived ammonia into the human brain, such studies do not provide information directly on the metabolic fate of the trapped ammonia in brain in vivo. However, several in vivo MRS studies have shown large increases in brain glutamine (or Glx) in hyperammonemic animals, ${ }^{112-114}$ and as previously noted in patients with a variety of hyperammonemic syndromes. ${ }^{48-54} \mathrm{Sev}$ eral of these studies revealed that at the same time, myoinositol (and in some cases choline-containing compounds) is decreased, possibly in an attempt by astrocytes to maintain osmotic balance. myo-Inositol is an idiogenic osmolyte that is exported during cell swelling to help restore cell volume, although the amount that can be exported may not always offset the increased osmols of glutamine that arise during hyperammonemia.

MRS studies have provided especially strong support for the hypothesis that excess glutamine is associated with neuropathological symptoms in hyperammonemic patients. For example, Connelly et al. ${ }^{48}$ showed that two children with symptomatic ornithine transcarbamylase deficiency had markedly increased brain glutamine, and in one child this glutamine was reduced with treatment. In the study of Shawcross et al., ${ }^{53} 14$ patients with liver cirrhosis were each administered an amino acid solution $(75 \mathrm{~g})$ designed to induce hyperammonemia. In addition to increased brain Glx and plasma ammonia, plasma glutamine was increased by the treatment. At $4 \mathrm{~h}$, eight patients exhibited memory deterioration. In patients who showed memory deterioration, the myo-inositol-to-creatine ratio in the brain was significantly lower at baseline than in those who did not exhibit deterioration. In contrast, the Glx-to-creatine ratio was significantly greater in brains of patients who did exhibit deterioration. The authors concluded that deterioration in memory test scores was greater in those with lower myo-inositol/creatine ratios and supports the hypothesis that the neuropsychological effects of induced hyperammonemia are determined by the limited residual capacity of further myo-inositol export to counteract the ammonia-induced increase in glutamine.

\section{Possible role of a toxic glutamine metabolite contributing to ammonia-induced neurotoxicity}

$\alpha$-Ketoglutaramate, the $\alpha$-keto acid analogue of glutamine produced via transamination of glutamine, is increased in the CSF of patients with liver disease by as much as fifty-fold. ${ }^{115-117}$ Moreover, the concentration of $\alpha$-ketoglutaramate in CSF correlates with degree of he- 
patic encephalopathy better than the concentration of ammonia or even glutamine. ${ }^{116}$ Vergara et al. ${ }^{115}$ reported that $\alpha$-ketoglutaramate may be neurotoxic. However, relatively enormous amounts of $\alpha$-ketoglutaramate were infused into the rat brain in that study. Thus, the possibility that excess $\alpha$-ketoglutaramate is a neurotoxic factor in liver disease/hyperammonemia needs to be reevaluated. Even if the compound proves to be relatively harmless, an understanding of its metabolic origin may shed light on biochemical mechanisms associated with glutamine neurotoxicity. Moreover, $\alpha$-ketoglutaramate may prove to be a useful biomarker for liver disease and other hyperammonemic syndromes (Kuhara and Cooper, unpublished results).

A "Trojan horse" theory has recently been proposed to account for ammonia neurotoxicity, based on studies of astrocytes in culture media containing excess ammonia. ${ }^{118}$ According to this theory, excess glutamine (i.e., the Trojan horse) is transported to mitochondria, wherein it is metabolized by phosphate-activated glutaminase (PAG) to glutamate and ammonia. The excess ammonia interferes with normal mitochondrial function, generating excessive reactive oxygen species/reactive nitrogen species (ROS/RNS), and inducing an MPT. A pathological loss of selective permeability produces astrocyte dysfunction, including cell swelling and death. ${ }^{18-125}$ In this theory, although glutamine is the villain, the noxious metabolite is ammonia that has (in effect) been redirected toward the mitochondrion. This theory is in accord with a central role of glutamine in ammonia neurotoxicity and therefore needs to be evaluated.

In support of the theory, PAG activity is present in mouse brain astrocytes in culture ${ }^{126}$ and has recently been demonstrated immunohistochemically to be present in astrocytes in the human brain. ${ }^{127}$ Astrocyte PAG seems to be similar to the neuronal form, except that it is not inhibited by ammonia. ${ }^{126}$ Moreover a distinct glutaminase has recently been reported to be present in mitochondria of astrocytes in culture. ${ }^{128}$ However, studies with acutely hyperammonemic animals do not support the Trojan horse theory. MRS studies with $\left[{ }^{15} \mathrm{~N}\right]$ ammonia suggest that the in vivo glutaminase activity in the brains of acutely hyperammonemic rats is actually quite low $(<1.1 \%$ the optimal activity reported in brain homogenates), ${ }^{129}$ presumably as a result of low phosphate levels, strong inhibition by glutamate, and feedback inhibition by excess ammonia in at least some populations of PAG. ${ }^{129-131}$ The study with $\left[{ }^{15} \mathrm{~N}\right]$ ammonia did not distinguish between the astrocyte and neuronal pools of glutamine. ${ }^{129}$ However, because the level of glutamine in astrocytes is likely to be quite high, the findings suggest a slow turnover of glutamine in the astrocytes in acute hyperammonemia. Moreover, rodents can survive very high levels of acutely administered ammonia when glutamine synthetase is inhibited. ${ }^{132} \mathrm{In}$ this study, the level of ammonia in astrocytes, including that in the mitochondrial compartment, would have been extraordinarily high.

The situation with chronic hyperammonemia is also not consistent with the theory. Acute ammonia intoxication in rats does not lead to an MPT in nonsynaptic brain mitochondria. ${ }^{133}$ Because astrocyte mitochondria represent only a small fraction of nonsynaptosomal mitochondrial, an MPT in astrocytic mitochondria might have been obscured in that study. Moreover, this experiment does not address the issue of whether MTP is a prominent feature in chronic hyperammonemia. Nevertheless, a prolonged MPT in astrocytes in chronic hyperammonemia seems unlikely. A prolonged MPT will result in dissipation of the mitochondrial proton gradient, loss of cellular ATP, loss of ion homeostasis, and ultimately necrotic cell death. ${ }^{134}$ However, as previously noted, no discernible losses in ATP and PCR reserves to only modest losses have been noted in hyperammonemic brain. Furthermore, patients severely encephalopathic from hyperammonemia regularly recover, unless cerebral edema has resulted in a degree of ICP that compromises the cardiovascular and respiratory centers in the brain stem. Also, as previously noted, primates subjected to a nonlethal encephalopathic dose of ammonia will eventually fully recover. ${ }^{98}$ Full recovery in deeply encephalopathic patients who are hyperammonemic from any cause is not uncommon. ${ }^{54,103,135,136}$ Although there is evidence of morphological changes to astrocytes in autopsied brains of patients who died of hepatic encephalopathy, there is little evidence of net astrocytic cell death. ${ }^{21,102}$

\section{MECHANISM OF HYPERAMMONEMIA- INDUCED CEREBRAL EDEMA-THE OSMOTIC GLIOPATHY THEORY}

\section{Background}

Cerebral edema in liver disease has been ascribed to a combination of toxic liver factors and an altered BBB. ${ }^{23}$ However, although there may be subtle hyperammonemia-induced changes in BBB uptake of ammonia ${ }^{32,59-62}$ and certain amino acids, ${ }^{137}$ hyperammonemic and hepatic encephalopathy may now be explained largely by the osmotic gliopathy theory. This theory exploits the suggestion of Voorhies et al. ${ }^{98}$ that intra-astrocyte accumulation of ions is, in some way, responsible for swelling. ${ }^{98}$ In brief, Brusilow, ${ }^{138}$ Watson et al., ${ }^{139}$ and Brusilow and Traystman ${ }^{140}$ proposed that the biochemical and neurological changes observed in experimental and clinical hyperammonemia states are a consequence of shifts of water into astrocytes as a result of intracellular glutamine synthesis and accumulation initiated by hyperammonemia of any cause. Astrocytes represent a large fraction of 
brain volume, and as previously noted they are specific sites in the brain for glutamine synthetase activity. ${ }^{106,107}$

The possibility that accumulation of glutamine may be toxic to the brain is consistent with prior work by Warren and Schenker, ${ }^{132}$ although it should be noted that Schenker and Brady ${ }^{141}$ later considered the astroglial changes and edema seen in hyperammonemia to be epiphenomena and not determinants of an altered mental state. Warren and Schenker ${ }^{132}$ showed that the median lethal dose $\left(\mathrm{LD}_{50}\right)$ of acutely administered ammonia in mice treated with MSO was 50\% higher than in the control mice that were administered ammonia alone. ${ }^{132}$ The neuroprotective effect of MSO against excess ammonia in rodents has been confirmed in a number of studies. ${ }^{82,142-}$ 153 The findings with MSO are fully consistent with the osmotic gliopathy theory. For example, MSO was shown to normalize water content in the brains of acutely hyperammonemic rats ${ }^{145}$ and to attenuate edema in portacaval-shunted rats exposed to an ammonia challenge. ${ }^{147}$ When astrocyte nuclear size was measured in place of water content in hyperammonemic rats, the results were similar; MSO treatment restored the swollen astrocytes to their normal size, even as the plasma ammonia increased (FIG. 2). ${ }^{101}$ Using the same experimental protocol, MSO attenuated potassium dyshomeostasis during rising levels of plasma ammonia. ${ }^{146}$ In addition to redressing osmotic stress and loss of potassium regulation, MSO prevented or ameliorated several other neuropathological changes in experimental animals subjected to acute hyperammonemia (Table 2). The ability of MSO to counteract the changes in increased cortical water content, astrocyte swelling, and extracellular $\mathrm{K}^{+}$in acutely hyperammonemic rats are shown in FIG. 3. The neuroprotective effect of MSO against acute hyperammonemia is evident despite remarkably high levels of plasma ammonia. The increase in plasma ammonia concentration at a time when MSO exerts its beneficial effect is a finding central to understanding the mechanism of ammoniainduced encephalopathy.

\section{Summary of the osmotic gliopathy theory}

Astrocyte glutamine synthesis is stimulated in response to hyperammonemia, and as a result of glutamine accumulation the astrocytes will swell. However, compliance by other cerebral structures will compensate for the increased volume, thereby avoiding or minimizing increases in ICP. ${ }^{154,155}$ Further increases in intra-astrocyte free glutamine, osmotic pressure, and cell volume will overcome compliance resulting in increases in ICP and progression of clinical encephalopathy. It should also be appreciated that individual astrocytes in the human brain are larger and send more processes to synapses than those in the rodent brain. ${ }^{156}$ The expanded neuropil enriched in astrocytes in layer I of human cerebral cortex results in an overall larger proportion of brain volume occupied by astrocytes. If the increase in glutamine is homogeneous among protoplasmic astrocytes, then the magnitude of intracranial hypertension is likely to be augmented in humans compared with the same degree of hyperammonemia in rodents. A summary of the osmotic gliopathy theory is given in FIG. 4.

In addition to intracranial hypertension, neurological function depends on maintaining normal astrocytic control of neuronal excitability by regulating extracellular potassium and neurotransmitter concentrations. Disturbances in these regulatory processes by astrocytes may be secondary to glutamine accumulation and astrocyte swelling, ${ }^{145}$ and recovery of these functions may lag behind decreases in ammonia. Hypothermia, which can prevent cerebral edema without reducing brain glutamine accumulation in a model of acute liver failure, ${ }^{157}$ may act to reduce energy demand, thereby permitting energydependent restoration of cell volume, ion homeostasis,

Table 2. Effects of the Glutamine Synthetase Inhibitor L-Methionine-S,R-sulfoximine on Neuropathological Changes in Acutely Hyperammonemic Rats*

\begin{tabular}{|c|c|c|}
\hline Change & Effect of MSO & References \\
\hline Cerebral edema and astrocyte swelling & Prevented or attenuated & $101,144,147$ \\
\hline Dysregulation of control of cerebral blood flow & Prevented & 148 \\
\hline Dysregulation of pial arteriolar $\mathrm{pCO}_{2}$ response & Prevented & 149,150 \\
\hline Brain potassium dyshomeostasis & Attenuated & 146 \\
\hline Acetylcholine insensitivity & Prevented & 151 \\
\hline Increase in glial fibrillary protein & Prevented & 152 \\
\hline Increase in connexin- 43 & No effect & 152 \\
\hline Decrease in cerebral metabolic rate for glucose & Prevented or partially prevented & 67,82 \\
\hline Altered BBB amino acid transport & Prevented & 82,153 \\
\hline
\end{tabular}

$\mathrm{BBB}=$ blood-brain barrier; $\mathrm{MSO}=\mathrm{L}$-methionine- $S, R$-sulfoximine.

*Except where noted, rats were subjected to short-term $(6 \mathrm{~h})$ hyperammonemia by infusion of ammonium acetate. In reference 82 , rats were administered MSO after porta-caval shunting. In reference 67, hyperammonemia was induced directly in rats by administration of MSO. In these animals, changes in the cerebral metabolic rate for glucose were expected to occur at $24 \mathrm{~h}$ as a result of the hyperammonemia, but were not observed. In reference 147, porta-caval-shunted rats were pretreated with MSO before challenge with ammonia. In references 152 and 153 , rats were subjected to pretreatment with MSO before a 24-h infusion of ammonium salts. 
A

\section{Treatment Protocols}

\section{Group 1: Control Rats; Black}

(Injection with sodium acetate)

Group 2: Hyperammonemic Rats; Red (Injection with ammonium acetate)

Group 3: MSO-protected Rats; Green (Injection with ammonium acetate plus MSO)

\section{Parameters Measured}

I. Brain fractional water content versus plasma $\left[\mathrm{NH}_{4}{ }^{+}\right]$

II. Astrocytic nuclear circumference versus plasma $\left[\mathrm{NH}_{4}{ }^{+}\right]$

III. Extracellular $\left[\mathrm{K}^{+}\right]$in parietal cortex versus plasma $\left[\mathrm{NH}_{4}{ }^{+}\right]$

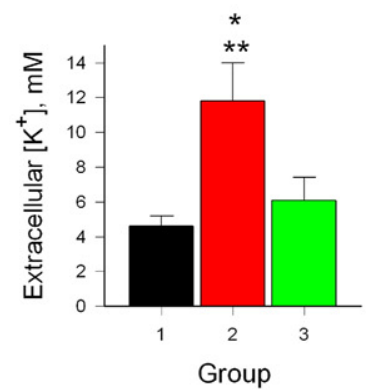

I
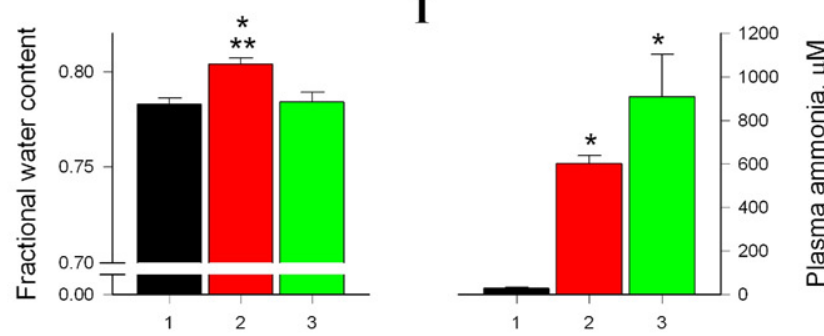

II
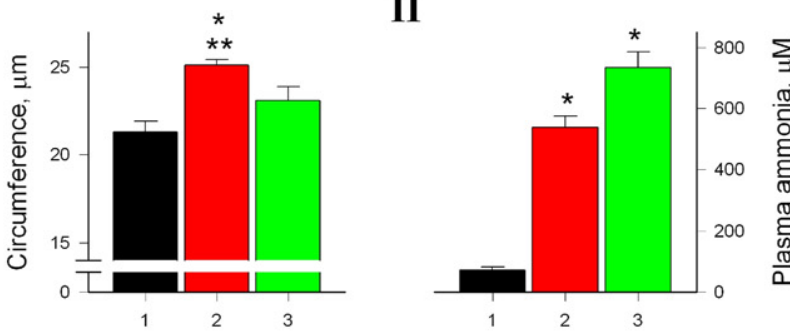

III

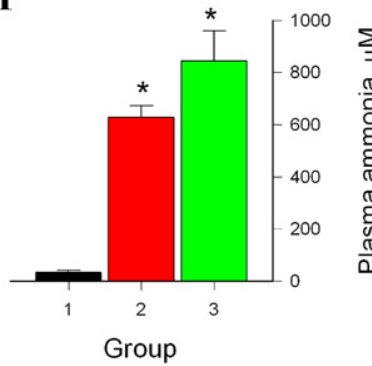

FIG. 3. (A) Protocol used to assess the neuroprotective effect of L-methionine-S,R-sulfoximine (MSO) against hyperammonemiainduced neuropathology; (B) parameters measured: (I) cortical fractional water, (II) astrocyte nuclear circumference, and (III) extracellular $\mathrm{K}^{+}$. Briefly, adult male Wistar rats were anesthetized, mechanically ventilated with $30 \%$ to $50 \% \mathrm{O}_{2}$, and the body temperature was maintained at $37^{\circ} \mathrm{C}$ for the duration of the experiment. Group 1 received sodium acetate (nonhyperammonemic control); group 2 received ammonium acetate; and group 3 received ammonium acetate plus MSO. For more details of infusion schedules and methods see: group 1, Takahashi et al ${ }^{145}$; group 2, Willard-Mack et al. ${ }^{101}$; and group 3, Sugimoto et al. ${ }^{146}$ The data are from these authors, but are plotted in a different manner. Values are reported as the mean \pm the standard error of the mean. ${ }^{\star} P<0.05$ relative to the sodium acetate infused group; ${ }^{* *} P<0.05$ ammonium acetate infused group relative to the sodium acetate infused group, and the ammonium acetate plus MSO group; ( $n=8$ to 37 ).

and neurotransmitter regulatory processes in the face of elevated glutamine.

\section{Hyperammonemia and hyperglutaminemia}

Hyperglutaminemia is invariably a consequence of hyperammonemia, ${ }^{158,159}$ as a result of the widespread occurrence of glutamine synthetase in liver and extrahepatic tissues. The glutamine released to the circulation is presumably an attempt by tissues to remove waste nitrogen in the presence of elevated and potentially toxic ammonia levels. Because the brain contains appreciable glutamine synthetase activity, it is not surprising that cerebral glutamine (or Glx) levels (as previously noted) are increased in hyperammonemic patients as assessed with MRS. Moreover, it has been shown by means of in vivo brain microdialysis that a profound increase in brain glutamine occurs in patients with acute liver failure and hyperammonemia. ${ }^{160}$ The elevation of brain glutamine concentrations correlated with ICP in these patients. ${ }^{160}$
Unfortunately, however, despite some preliminary encouraging data, ${ }^{54}$ there seems to be no complete MRS study of the temporal relationships among brain glutamine levels, plasma glutamine levels, plasma ammonia levels, and degree of encephalopathy in hyperammonemic patients. It is anticipated that MRS techniques will become increasingly used to evaluate mechanisms of ammonia-induced encephalopathy in patients, and to assess measures designed to redress excess brain glutamine and the attendant edema. ${ }^{161}$

\section{POSSIBLE CONFOUNDING FACTORS ASSOCIATED WITH THE OSMOTIC GLIOPATHY THEORY}

Although MRS techniques are becoming progressively more important in elucidating the mechanism of hepatic encephalopathy, they are also beginning to raise intriguing questions. Rovira et al. ${ }^{161}$ present convincing 


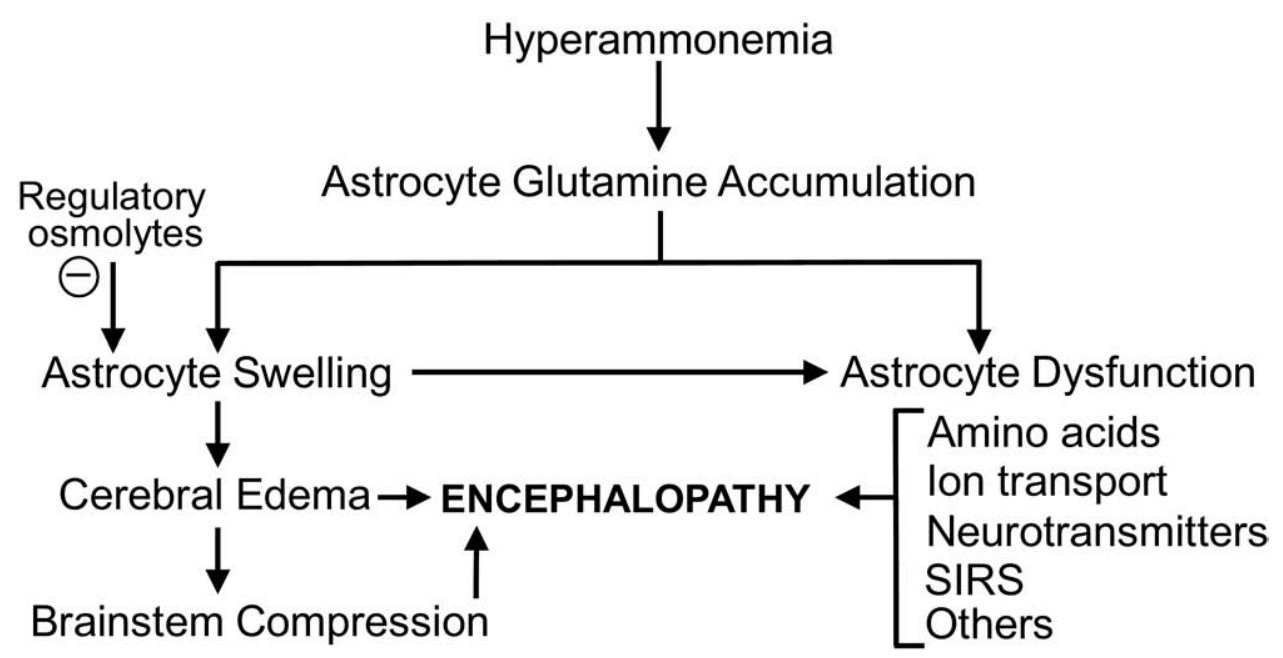

FIG. 4. Increased cerebral ammonia concentrations as a result of hyperammonemia result in astrocyte swelling in response to the osmotic effects of accumulated glutamine. Swollen astrocytes have two broad consequences; they have a mass effect, but for a limited time offer no ICP threat as predicted by the Monro-Kellie hypothesis. Increased ICP resulting from astrocyte swelling is delayed by the compliance of intracranial tissues. Additional glutamine accumulation will overcome brain compliance and result in increased intracranial pressure and accompanying encephalopathy. Cell swelling and increased ICP affect many cellular functions and structures. These are slow to attain their normal configuration and function once the hyperammonemia decreases and excess brain glutamine dissipates. Regulatory organic osmolytes (e.g., myo-inositol) are down-regulated to compensate for the increased concentration of glutamine. SIRS $=$ systemic inflammatory response syndrome. Modified from Brusilow. ${ }^{41}$

evidence that MRS data are fully consistent with the osmotic gliopathy theory in patients with acute liver failure. Thus, several MRS techniques unequivocally show large increases in water content in these patients that are fully consistent with swelling of an intracellular compartment (i.e., astrocytes). ${ }^{161}$ On the other hand, the situation is somewhat more complicated in patients with chronic liver failure. MRS studies on patients with chronic liver disease invariably show increased brain glutamine (or Glx), and where measured there was decreased brain myo-inositol/choline-containing compounds, which are findings indicative of osmotic stress. ${ }^{161}$ However, as we previously pointed out in Table 2, the cerebral edema is less pronounced in patients with chronic liver failure than in the acute liver failure group. Moreover, MRS studies with a technique known as diffusionweighted imaging suggest that this small increase in brain water in chronic liver disease patients may be largely extracellular and is more pronounced in the more severe grades of encephalopathy. ${ }^{161-164}$ One inference from these studies is that most of the excess cerebral water in these patients seems to be in the extracellular space and, therefore, the astrocytes may be osmotically normal. However, we believe that the findings do not necessarily contradict the osmotic gliopathy hypothesis for the chronically hyperammonemic condition. We suggest that there is indeed an initial very pronounced osmotic stress in the astrocytes due to increased glutamine synthesis in these cells, as occurs in acute liver failure/ acute hyperammonemia. This can readily be seen from the data presented in FIG. 2. However, with time in the chronically hyperammonemic patients, there is a gradual compensation as reflected by decreased myo-inositol/ choline-containing compounds in astrocytes to compensate for the glutamine-induced osmotic stress. This compensation is accompanied by increased water in the extracellular space. However, this compensation can not be complete, because even in the chronically hyperammonemic state there is evidence that astrocyte swelling occurs, which may be more pronounced in the more severe disease. ${ }^{55,93,95,97}$

One other point regarding glutamine levels in astrocytes needs to be clarified. In the glutamine cycle (depicted by red arrows in FIG.1) glutamate released from neurons is taken up largely by astrocytes and converted therein to glutamine. This glutamine is released in part to the extracellular fluid to be taken up by neurons where it is converted to glutamate, completing the cycle. It has been estimated from in vivo ${ }^{13} \mathrm{C}$ and ${ }^{15} \mathrm{~N}$ nuclear magnetic resonance (NMR) studies in rodents and ${ }^{13} \mathrm{C}$ NMR in humans that brain glutamine synthesis is substantial and that the total glutamate (and GABA)-glutamine cycling flux, necessary to replenish neurotransmitter glutamate (and GABA), accounts for $>80 \%$ of net glutamine synthesis. ${ }^{165} \mathrm{~A}$ key regulator of the cycle is a glutamine transporter in the astrocyte plasma membrane. This transporter (system N/A transporter 3 [SNAT3]; formerly known as SN1) facilitates the efflux of glutamine from astrocytes to the extracellular space. ${ }^{166-168}$ The transporter carries out $\mathrm{Na}^{+}$glutamine co-transport $-\mathrm{H}^{+}$ anti-port. Work by Kanamori and Ross ${ }^{169}$ using combined ${ }^{15} \mathrm{~N}-\mathrm{NMR}$ and microdialysis techniques showed in rats that there is a partial suppression of SNAT3-mediated transport of glutamine from astrocytes to the extra- 
cellular fluid in the presence of acute hyperammonemia. Clearly, the SNAT3 transporter can not compensate for the dramatic increase in glutamine in the astrocyte compartment in experimental animals subjected to acute ammonia intoxication or in patients with acute liver disease. However, what is the situation in chronic low-grade hyperammonemia? Based on the studies of Kanamori and Ross, we suggest it is likely that a decrease in the activity of the SNAT3 transporter activity will also occur in chronically hyperammonemic brain. Brain glutamine synthetase $K_{\mathrm{m}}$ values have been reported to be $1.8 \mathrm{mM}$ and $2.3 \mathrm{mM}$ for ammonia and ATP, respectively. ${ }^{170}$ Brain ATP levels are approximately $2.4 \mathrm{mM}$, and they do not change dramatically in the chronically hyperammonemic rat brain. However, the ammonia concentration in the astrocyte compartment is estimated to be $<0.2$ $\mathrm{mM}$ and to increase greatly during hyperammonemia. ${ }^{24}$ Thus, as the ammonia concentration in the astrocyte compartment increases, there will be a corresponding increase in astrocyte glutamine synthesis. This increased glutamine synthesis coupled with the suppression of the SN3 transporter will ensure that during chronic hyperammonemia there will be an increased steady state level of glutamine in the astrocytes. This increased glutamine in astrocytic compartment will create an osmotic stress, as previously mentioned, that can only partially be redressed by loss of myo-inositol/choline-compounds.

Although we have strongly argued (as previously described) that the osmotic gliopathy theory robustly accounts for the CNS swelling in acute and chronic forms of hyperammonemic encephalopathy, we have not addressed the issue of how the swelling induces neurological dysfunction. Häussinger and Schliess ${ }^{171}$ sum up a prevailing view by stating "The low-grade cerebral oedema [in hyperammonemia] is accompanied by an increased production of reactive oxygen and nitrogen species..., which trigger multiple protein and RNA modifications, thereby affecting brain function. The action of ammonia, inflammatory cytokines, benzodiazepines and hyponatreamia integrates at the level of astrocyte swelling and oxidative stress." ${ }^{171}$ Although it seems that Häussinger and Schliess ${ }^{171}$ agree on the central importance of swelling in hyperammonemic encephalopathy, in our opinion it is difficult to envisage how all of the suggested modifications resulting from this swelling (some of which would be quite severe) can account for the fact that hyperammonemic encephalopathy is often reversible, even for patients who have been comatose for several days. We make no claims as to the molecular mechanism by which astrocyte swelling induces encephalopathy. The important point we wish to make is that whatever the mechanism, hyperammonemic encephalopathy is reversible up to a point. Complete recovery is possible provided that interventions can rapidly redress the osmotic imbalance and the initial insult is not too severe.

Although most authors in the field now agree that excess glutamine in the astrocyte compartment contributes to an osmotic stress in hyperammonemic syndromes, others suggest that factors in addition to astrocyte swelling must also contribute to ammonia-induced encephalopathy, some perhaps much more importantly. For example, see the review by Zwingmann and Butterworth. ${ }^{45}$ Such factors may include inflammation and/or alterations in GABAergic tone, BBB function, electrophysiological properties, NMDA receptors, and nitric oxide synthase. ${ }^{45,78,114,172,173}$ Two particularly germane studies may be mentioned here. In one study, Sonnewald et al. ${ }^{174}$ used NMR techniques to show that after infusion of $\left[2-{ }^{13} \mathrm{C}\right]$ acetate into portacaval-shunted rats, the label in glutamine was increased, whereas that in glutamate, aspartate, and GABA was decreased compared to that of the control rats. Because astrocytes are the primary site for metabolism of acetate, and the major pools of glutamate, aspartate, and GABA are neuronal, the data suggest that metabolite trafficking from astrocytes to neurons is impaired in portacaval-shunted rats. The authors suggested that such impairments and consequent disruption of amino acid neurotransmitter function could play a role in the pathophysiology of the neurological symptoms characteristic of hepatic encephalopathy. ${ }^{174}$ In another study, Kanamori et al. ${ }^{175}$ infused unlabeled ammonium acetate $(5.6 \mathrm{mmol} / \mathrm{h} / \mathrm{kg})$ into rats for 3 hours, followed by 3 hours of infusion of the same amount of ${ }^{15} \mathrm{~N}$-labeled ammonium acetate. Using NMR techniques, the authors showed a saturable increase in brain glutamine. As brain glutamine increased, there was a concomitant rise in brain impairment. Grade III encephalopathy occurred when brain glutamine reached a maximum. Progression to grade IV encephalopathy was accompanied by a large increase in brain ammonia, but no further increase in brain glutamine. The authors concluded that the severity of brain impairment correlates with brain ammonia and not with brain glutamine, and that the excess ammonia interferes with neuronal properties. ${ }^{175}$ However, we suggest that in this experiment, it is possible that there was a delay in the neurological consequences of an enlarged astrocytic glutamine pool. Interestingly, it is now apparent that astrocytes are antigen-presenting cells within the CNS. ${ }^{176}$ Whether prolonged hyperammonemia alters this function remains to be determined.

Most of the conclusions of those authors who espouse additional mechanism to account for hyperammonemiainduced encephalopathy are derived from studies of animal models, cells in culture, or brain tissue slices. The extent to which other mechanisms besides osmotic stress contribute to the ammonia-induced astrocyte dysfunction in the human brain in vivo, or whether the osmotic stress 
is a cause of many of the metabolic/pathophysiological disturbances, is open to debate. In our opinion, the majority of MRS studies of patients with hyperammonemic syndromes are fully consistent with the osmotic gliopathy theory, especially regarding acute hyperammonemia. As we have emphasized in this review, more detailed MRS studies are urgently needed to more accurately assess the relationships among plasma ammonia, brain glutamine, and swelling, and to settle ongoing controversies for the ultimate benefit of the patient. Such an assessment will be of immeasurable help in providing the best treatment for hyperammonemic patients.

\section{POSSIBLE USE OF A GLUTAMINE SYNTHETASE INHIBITOR AS A PHARMACOLOGICAL AGENT}

\section{Background}

A major recommendation of the "acute liver failure group" is to treat the increased ICP accompanying acute liver failure by osmotic therapy. ${ }^{177}$ As previously emphasized, the neuropathological consequences of astrocytic hyperammonemia-induced swelling are not entirely clear yet. However, there are certain similarities in the neuropathological consequences between ischemia and hyperammonemia, one of which is swollen astrocytes. Kimelberg ${ }^{178}$ and Kimelberg et al. ${ }^{179}$ suggest that swollen astrocytes may release neurotransmitters (rather than take them up) and ATP via volume-activated anion channels (VRACs). These authors suggest that preventing this swelling by targeting VRACs may be of therapeutic benefit. By the same token, the targeting of VRACs may also be useful in patients with liver disease or other hyperammonemic syndromes.

Another possible strategy is to target glutamine synthetase. Because excess glutamine is a major contributing factor to increased ICP, intervention with a glutamine synthetase inhibitor might be beneficial in these patients. In this regard, Eisenberg et al. ${ }^{180}$ have provided a remarkably comprehensive list of glutamine synthetase inhibitors, some of which might be clinically effective. One such candidate is MSO. Most glutamine in brain is contained in the astrocyte compartment, and MSO potently decreases this pool of glutamine. ${ }^{181}$ Given the finding that MSO is protective against a wide range of ammonia-induced neuropathological changes in experimental animals (see Table 2 and references cited therein), it would seem that this compound might be especially useful.

However, the concept that MSO can reduce swelling in astrocytes has been questioned by some authors. ${ }^{182}$ Thus, Zielińska et al. ${ }^{182}$ noted that MSO treatment of rat cortical slices in the presence of ammonia increased the glutamine content without causing cell swelling. The authors stated that "MSO did not affect cell volume in the slices, showing that Gln [glutamine] retention is not as a rule a causative factor in cerebral edema." ${ }^{182}$ In our opinion, all this study shows is the inappropriateness of the ex vivo model the authors used. Contrary to the authors' statement, MSO is known to ameliorate ammonia-induced astrocyte swelling in vivo ${ }^{101,144,147}$ and decrease brain glutamine content. ${ }^{57,73,183,184}$

A more serious criticism is the well known observation that MSO at high doses is a convulsant in experimental animals. ${ }^{185-187}$ Thus, its safety in humans must be addressed. Sellinger and colleagues have suggested that the convulsant action of MSO in rodents is not due to inhibition of glutamine synthetase. ${ }^{188}$ Rather they have proposed that inasmuch as methionine is protective against a convulsive dose of MSO in rodents ${ }^{188,189}$ and MSO decreases the level of $S$-adenosyl methionine, ${ }^{188}$ the convulsant properties of MSO may be related to interference with key methylation reactions in brain. ${ }^{189}$ On the other hand, Meister and co-workers have argued strongly that the convulsant activity of MSO is in fact due to inhibition of glutamine synthetase. ${ }^{190,191}$ Complicating the picture further are the findings that MSO can be metabolized in vitro and in vivo to products of unknown toxicity. ${ }^{192,193}$ Notwithstanding these cautions, the available evidence, as documented in the following section, suggests that pharmacological doses of MSO will be safe in humans.

The susceptibility to MSO-induced seizures varies greatly among species, with monkeys and rats being 100 times less susceptible than dogs. ${ }^{185}$ In studies carried out in the 1940s, no untoward effects were noted in adult humans and children given food containing agenized flour (i.e., flour treated with $\mathrm{NCl}_{3}$, which after intestinal digestion generates considerable amounts of MSO). ${ }^{194,195}$ Notably, in the study of Pollack, ${ }^{195}$ one adult female and two adult male epileptic volunteers were fed half their body weight in agenized flour baked into bread and cookies, fortified with minerals and vitamins for a period of 2 to 3 months. No seizure activity was noted. On the other hand, dogs fed a similar diet showed severe signs of neurotoxicity within 18 hours. In this same study, cats and monkeys were much more resistant than dogs to the toxic effects of agenized flour. ${ }^{195}$

The possible safe use of MSO as a therapeutic agent in patients is also suggested by the work of Blin et al. ${ }^{196}$ who showed that 4-week old mice treated with a nonconvulsive dose of MSO (20 mg/kg intraperitoneally; thrice weekly) for 10 weeks exhibited no obvious behavioral or spatial memory deficits, despite $80 \%$ loss of brain glutamine synthetase activity. In other studies, it was shown that treatment with nonconvulsive doses of MSO resulted in inhibition of brain glutamine synthetase by $\sim 64 \%$ to $86 \%$ in rats, ${ }^{67,150,152}$ and maximally $85 \%$ in mice. ${ }^{192}$ Moreover, in all the studies listed in Table 2 showing protective effects of MSO against ammonia intoxication in rats, the dose of the 
A

\section{Treatment Groups}

Group 1: Rats - Series 1; Black circles

Group 2: Rats - Series 2; Red circles

Group 3: Monkeys; Green circles

Methods

1. MSO in saline was injected intraperitoneally

2. Rats were sacrificed at $24 \mathrm{~h}$

3. Monkeys were sacrificed at

$24 \mathrm{~h}(2.5 \mathrm{mg} / \mathrm{kg}$ dose $)$

$4 \mathrm{~h}(5 \mathrm{mg} / \mathrm{kg}$ dose)

$4 \mathrm{~h}$ (10 mg/kg dose)

\section{Brain glutamine synthetase activity was measured and compared to controls}

B

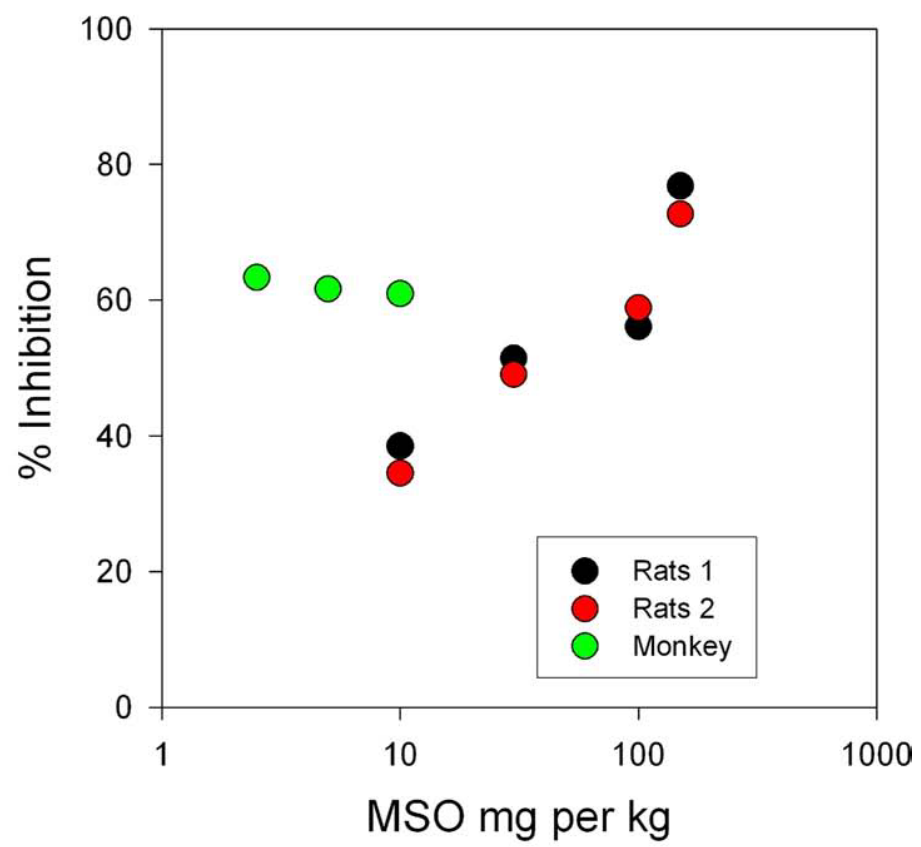

FIG. 5. Comparison of the effect of L-methionine-S,R-sulfoximine (MSO) on the specific activity of brain glutamine synthetase in rats and monkeys. One monkey received $2.5 \mathrm{mg} / \mathrm{kg}$ MSO intravenously. Videotape analysis of this monkey for a $24-\mathrm{h}$ period after administration of the MSO revealed no obvious changes in behavior, grooming, or feeding. At 24 hours the monkey was sacrificed, and a cortical biopsy was removed for measurement of glutamine synthetase activity. Cortical biopsies (100 mg) were also obtained from one hemisphere before MSO administration and 4 hours after intravenous administration of MSO from the opposite hemisphere in two monkeys maintained under anesthesia with halothane and nitrous oxide. One of these monkeys received 10 $\mathrm{mg} / \mathrm{kg} \mathrm{MSO}$ and the other monkey received $5 \mathrm{mg} / \mathrm{kg} \mathrm{MSO}$. The specific activities of cortex glutamine synthetase in the two monkeys before receiving MSO were 35.6 and $33.1 \mathrm{U} / \mathrm{g}$ wet weight, in which 1 unit corresponds to the amount of $\gamma$-glutamylhydroxamate formed per 15 minutes at $37^{\circ} \mathrm{C}$ in a reaction mixture containing glutamate, ATP, and hydroxylamine (in place of ammonia) as defined by Rao and Meister. ${ }^{192}$ The specific activities of cortical glutamine synthetase in the MSO-treated monkeys were $13.9,12.7$, and $12.6 \mathrm{U} / \mathrm{g}$ wet weight in the $10 \mathrm{mg} / \mathrm{kg} \mathrm{MSO}, 5 \mathrm{mg} / \mathrm{kg} \mathrm{MSO}$, and $2.5 \mathrm{mg} / \mathrm{kg} \mathrm{MSO}$ groups, respectively. The monkeys were euthanized by overdose with a barbiturate. Cortical glutamine synthetase activity was also measured in freezeclamped biopsies from anesthetized rats $3 \mathrm{~h}$ after MSO treatment, as outlined in reference 145. These experiments were approved by the Johns Hopkins University IUCAC.

glutamine synthetase inhibitor was subconvulsive. It is possible that seizures occur only when a critical loss of glutamine synthetase activity occurs in specific brain regions. Prolonged (28 days) microinfusion of MSO into rat hippocampus was associated with a high level of convulsions at a time when glutamine synthetase activity was inhibited $82 \%$ to $97 \% .{ }^{197}$ However, the levels administered to hippocampus were extreme, and localized depletion of brain glutamine synthetase activity to such an extent is not likely to occur with more conventional routes of MSO administration.

Additional evidence for the hypothesis that MSO may be a therapeutic agent is suggested from the data shown in FIG. 5. This figure summarizes the data obtained from a preliminary study comparing the inhibitory effect of different doses of MSO on brain glutamine synthetase activity in rats and nonhuman primates. In this study, doses of MSO $(2.5 \mathrm{mg} / \mathrm{kg})$ produced the same degree of inhibition of brain glutamine synthetase in nonhuman primates (rhesus monkeys) as did $100 \mathrm{mg} / \mathrm{kg}$ in the rats, suggesting that subconvulsant doses of MSO may be more effective inhibitors of glutamine synthetase in primates. This finding is consistent with that of Gershoff and Elvehjem, ${ }^{185}$ who showed MSO to be safe in nonhuman primates at a dose of $50 \mathrm{mg} / \mathrm{kg}$. In three rhesus monkeys in which glutamine synthetase activity was measured in brain cortical biopsies (present work), approximately $60 \%$ of the glutamine synthetase in brain cortex was inhibited by MSO, even at the highest dose of $10 \mathrm{mg} / \mathrm{kg}$ (FIG. 5). Biopsies were obtained at 4 hours after injection of 5 or $10 \mathrm{mg} / \mathrm{kg}$ of MSO, and at 24 hours after injection of $2.5 \mathrm{mg} / \mathrm{kg}$ MSO. The monkey monitored for 24 hours exhibited normal activity and appetite. These data are preliminary and require repetition. Nevertheless, the accumulated evidence suggests that it should be possible to safely tailor doses of MSO to humans, such that a critical loss of glutamine synthetase can be achieved without the side effects of debilitating seizures.

\section{Clinical and pharmacological considerations}

Although MSO has proven to be an invaluable biochemical tool that has helped establish excess glutamine 
as a major factor in hyperammonemic encephalopathy in experimental animals, it has some drawbacks. As previously noted, MSO can be metabolized. Thus, one possibility is that metabolic products contribute to the convulsant activity of MSO. However, this possibility is apparently ruled out by the fact that the glutamine synthetase inhibitor $\alpha$-ethyl-MSO, which is a nonmetabolizable analogue of MSO at high doses, also causes convulsions in rats. ${ }^{191}$ The early studies with MSO were carried out with a D,S; D,R; L,S; L,R mixture of diastereoisomers. Most studies with MSO for the last few decades have been carried out with a mixture of the L,S; $\mathrm{L}, \mathrm{R}$ diastereoisomers. However, only the $\mathrm{L}, \mathrm{S}$ isomer is an inhibitor of glutamine synthetase, and it is very difficult to separate the two diastereoisomers. ${ }^{190}$ Given the recent drive by pharmaceutical companies to synthesize only biological active isomers as drug candidates, the mixture of diastereoisomers in currently available MSO is a disadvantage, and the same considerations also apply to $\alpha$-ethyl-MSO. Nevertheless, until a potent, selective, nonmetabolizable, single isomeric glutamine synthetase inhibitor that readily crosses the BBB can be developed, MSO should be considered for clinical use. We understand the reluctance of physicians and funding agencies to carry out clinical trials on a compound that is based on animal studies and is a potential convulsant in humans at high doses. Nevertheless, we would like to point out that there is currently no evidence that any human being has been irreparably harmed by MSO, despite the previously mentioned studies carried out with MSO in the 1940s (references: Newell et al. ${ }^{194}$ and Pollack ${ }^{195}$ ) that would not be permissible by today's standards. More studies on human toxicity are required. In the meantime, we strongly urge the medical community to consider using MSO to treat severely ill patients with acute liver failure who would otherwise die. Perhaps as an added safeguard, an anticonvulsant could be co-administered. If the convulsant activity is due to the presence of excessive glutamate in the extracellular fluid, then a compound that activates the GABAergic system might be appropriate.

\section{SUMMARY}

The crucial step in the development of encephalopathy in hyperammonemic states, from whatever cause, is increased activity of astrocyte glutamine synthetase and possibly ammonia-induced inhibition of glutaminase. The accumulated glutamine poses osmotic stress to the astrocyte and the brain with the dire consequences of cerebral edema and increased ICP. There are also a number of other consequences of ammonia toxicity, some of which are related to glutamine, including alterations in energy metabolism and the possibility of a neurotoxic glutamine metabolite, but their connection to the clinical picture is cloudy. Clinical intervention to redress excess brain glutamine, particularly in severe cases of liver disease, may be possible by treatment with MSO, a potent glutamine synthetase inhibitor. However, little is known about its pharmacology and toxicology in humans. Other possible glutamine synthetase inhibitor candidates could also be evaluated. Detailed MRS studies of hyperammonemic patients are urgently needed to establish more precise temporal relationships among plasma ammonia, blood glutamine, and brain glutamine. Such studies should be helpful in designing more effective treatments of hyperammonemic patients and possible interventions with glutamine synthetase inhibitors.

\section{Disclosure}

No potential conflict of interest relevant to this article was reported by A.J.L.C. Authors R.J.T., R.C.K., and S.W.B. are co-authors of a United States Patent (No. 6,875,792, issued April 5, 2005) entitled "Dosage of L-methionine $S$-sulfoximine," wherein the possibility of using MSO as a clinical agent in hyperammonemic encephalopathies is proposed. However, author S.W.B. shares of the patent were sold in 2002, and he does not have any current financial interest in MSO.

Acknowledgements: The authors thank Dr. Owen W. Griffith (Medical College of Wisconsin) for helpful suggestions and Dr. Boris F. Krasnikov for help in construction of some of the figures. Some of the authors' work mentioned in this review was supported by the National Institutes of Health grants (Grant No. DK 16739 [AJLC] and Grant No. NS25275 [RCK, RJT, SWB]).

\section{REFERENCES}

1. van Caulaert $\mathrm{C}$, Deviller C. Ammoniémie expérimentale après ingestion de chlorure d'ammonium chez l'homme à l'état normal et pathologique. Compt Rend Soc Biol (Paris) 1932;111:50-2.

2. van Caulaert C, Deviller C, Halff M. Troubles provoqués par l'ingestion de sels ammoniacaux chez l'homme atteint de cirrhose de Laënnec. Compt Rend Soc Biol (Paris) 1932;111:739-40.

3. Kirk E. Amino acid metabolism in liver disease. Acta Med Scand Suppl 1936;77:1-147.

4. Mullen KD. Review of the final report of the 1998 Working Party on definition, nomenclature and diagnosis of hepatic encephalopathy. Aliment Pharmacol Ther 2007;25(suppl 1):11-6.

5. Gabuzda GJ Jr, Phillips GB, Davidson CS. Reversible toxic manifestations in patients with cirrhosis of the liver given cationexchange resins. New Engl J Med 1952;246:124-30.

6. Phillips GB, Schwartz BR, Gabuzda GJ Jr, Davidson CS. The syndrome of impending hepatic coma in patients with cirrhosis of the liver given certain nitrogenous substances. N Engl J Med 1952;247:239-46.

7. Shih V. Hereditary urea cycle disorders. In: The urea cycle. Grisolía S, Baguena R, Mayor F, eds. New York: John Wiley \& Sons, 1976:369-70.

8. Mitchell RB, Wagner JE, Karp JE, et al. Syndrome of idiopathic hyperammonemia after high-dose chemotherapy: review of nine cases. Am J Med 1988;85:662-7.

9. Nott L, Price TJ, Pittman K, Patterson K, Fletcher J. Hyperammonemia encephalopathy: An important cause of neurological deterioration following chemotherapy. Leuk Lymphoma 2007;48: 1702-11.

10. Samtoy B, DeBeukelaer MM. Ammonia encephalopathy secondary to urinary tract infection with Proteus mirabilis. Pediatrics 1980;65:294-7. 
11. Sato S, Yokota C, Toyoda K, Naganuma M, Minematsu K. Hyperammonemic encephalopathy caused by urinary tract infection with urinary retention. Eur J Int Med 2008;19:e78-9.

12. Vossler DG, Wilensky AJ, Cawthon DF, et al. Serum and CSF glutamine levels in valproate-related hyperammonemic encephalopathy. Epilepsia 2002;43:154-9.

13. Segura-Bruna N, Rodriguez-Campello A, Puente V, Roquer J. Valproate-induced hyperammonemic encephalopathy. Acta Neurol Scand 2006;114:1-7.

14. Lamiell JJ, Ducey JP, Freese-Kepczyk BJ, Musio F, Hansberry KL. Essential amino acid-induced adult hyperammonemic encephalopathy and hypophosphatemia. Crit Care Med 1990;18: $451-2$.

15. Alonso EM, Squires RH, Whitington PF. Acute liver failure in children, in: Liver disease in children, 3rd edit. Suchy FJ, Sokol RJ, Balistreri WF, eds. Philadelphia: Lippincott, 2008:71-96.

16. Lee WM. Acute liver failure. N Engl J Med 1993;329:1862-72.

17. Sherlock S, Dooley J, eds. Diseases of the liver and biliary system. London: Blackwell Science, 1996:94-5.

18. Ferenci P, Herneth A, Steindl P. Newer approaches to therapy of hepatic encephalopathy. Semin Liver Dis 1996;16:329-38.

19. Bessman SP. Ammonia metabolism in animals. In: Inorganic nitrogen metabolism. McElroy WD, Glass B, eds. Baltimore, MD: The Johns Hopkins Press, 1956:408-36.

20. Bessman SP. Blood ammonia. Adv Clin Chem 1959;2:135-80.

21. Adams RD, Foley JM. The neurological disorder associated with liver disease. Res Publ Assoc Res Nerv Ment Dis Proc 1953;32: $198-237$.

22. McDermott WV Jr, Adams RD. Episodic stupor associated with an Eck fistula in the human with particular reference to the metabolism of ammonia. J Clin Invest 1954;33:1-9.

23. Fraser CL, Arieff AI. Hepatic encephalopathy. N Engl J Med 1985;313:865-73.

24. Cooper AJL, Plum F. Biochemistry and physiology of brain ammonia. Physiol Rev 1987;67:440-519.

25. Lockwood AH. Ammonia-induced encephalopathy. In: Cerebral energy metabolism and metabolic encephalopathy. McCandless DW, ed. New York: Plenum Press, 1985:203-27.

26. Grisolía S, Felipo V, Miñana M-D, eds. Cirrhosis, hepatic encephalopathy, and ammonium toxicity. advances in experimental medicine and biology, vol 272. New York: Plenum Press, 1990.

27. Bengtsson F, Jeppsson, Almdal T, Vilstrup H, eds. Progress in hepatic encephalopathy and metabolic nitrogen exchange. Boca Raton, FL, CRC Press, 1991.

28. Conn HO, Bircher J, eds. Hepatic encephalopathy. Bloomington, IL: Medi-Ed Press, 1994:43-61.

29. Capocaccia L, Merli M, Riggio O, eds. Advances in hepatic encephalopathy and metabolic nitrogen exchange. Boca Raton, FL, CRC Press, 1995.

30. Felipo V, Butterworth RF. Neurobiology of ammonia. Prog Neurobiol 2002;67:259-79.

31. Felipo V, Butterworth RF. Mitochondrial dysfunction in acute hyperammonemia. Neurochem Int 2002;40:487-91.

32. Lockwood AH. Blood ammonia levels and hepatic encephalopathy. Metab Brain Dis 2004;19:345-9.

33. Brusilow SW. Determination of urine orotate and orotidine and plasma ammonium. In: Techniques in diagnostic human biochemical genetics: a laboratory manual. Hommes FA, ed. New York: Wiley-Liss, 1991:345-57.

34. Batshaw ML, Brusilow S, Waber L, et al. Treatment of inborn errors of urea synthesis. N Engl J Med 1982;306:1387-92.

35. Msall M, Batshaw L, Suss R, Brusilow SW, Mellits ED. Neurologic outcome in children with inborn errors of urea synthesis. Outcome of urea cycle enzymopathies. N Engl J Med 1984;310:1500-5.

36. Butterworth RF, Giguère JF, Michaud J, Lavoie J, Layrargues GP. Ammonia: key factor in the pathogenesis of hepatic encephalopathy. Neurochem Pathol 1987;6:1-12.

37. Brusilow SW, Maestri NE. Urea cycle disorders: Diagnosis, pathophysiology, and therapy. Adv Pediatr 1996;43:127-70

38. Butterworth RF. Complications of cirrhosis. III hepatic encephalopathy. J Hepatol 2000;32:171-80.

39. Häussinger D, Kircheis G, Fischer R, Schleiess F, vom Dahl S. Hepatic encephalopathy in chronic liver disease: a clinical man- ifestation of astrocyte swelling and low grade cerebral edema? J Hepatol 2000;32:1035-8.

40. Weissenborn K, Ennen JC, Schomerus H, Rückert N, Hecker H Neuropsychological characterization of hepatic encephalopathy. J Hepatol 2001;34:768-73.

41. Brusilow SW. Hyperammonemic encephalopathy. Medicine 2002;81:240-9.

42. Albrecht J, Jones EA. Hepatic encephalopathy: molecular mechanisms underlying the clinical syndrome. J Neurol Sci 1999;30:138-46.

43. Jalan R, Shawcross D, Davis D. The molecular pathogenesis of hepatic encephalopathy. Int J Biochem Cell Biol 2003;35: $1175-81$.

44. Blei AT. Brain edema in acute liver failure. Crit Care Clin 2008; 24:99-114.

45. Zwingmann C, Butterworth R. An update on brain glutamine synthesis and its relation to cell-specific energy metabolism in the hyperammonemic brain: Further studies using NMR spectroscopy. Neurochem Int 2005;47:19-30.

46. Maestri NE, Clissold D, Brusilow SW. Neonatal onset ornithine transcarbamylase deficiency: A retrospective analysis. J Pediatr 1999;134:268-72.

47. Lavoie J, Giguère JF, Layrargues GP, Butterworth RF. Amino acid changes in autopsied brain tissue from cirrhotic patients with hepatic encephalopathy. J Neurochem 1987;49:692-7.

48. Connelly A, Cross JH, Gadian DG, Hunter JV, Kirkham FJ, Leonard JV. Magnetic resonance spectroscopy shows increased glutamine in ornithine carbamoyl transferase deficiency. Pediatr Res 1993;33:77-81.

49. Tarasów E, Panasiuk A, Siergiejczyk L, et al. MR and ${ }^{1} \mathrm{H}$ MR spectroscopy of the brain in patients with liver cirrhosis and early stages of hepatic encephalopathy. Hepatogastroenterology 2003; 50:2149-53.

50. Wong YC, Au WL, Xu M, Ye J, Lim CC. Magnetic resonance spectroscopy in adult-onset citrullinemia: elevated glutamine levels in comatose patients. Arch Neurol 2007;64:1034-7.

51. Ross BD, Jacobson S, Villamil F, et al. Subclinical hepatic encephalopathy: proton MR spectroscopic abnormalities. Radiology 1994;193:457-63.

52. Córdoba J, Sanpedro F, Alonso J, Rovira A. ${ }^{1} \mathrm{H}$ magnetic resonance in the study of hepatic encephalopathy in humans. Metab Brain Dis 2002;17:415-29.

53. Shawcross DL, Balata S, Olde Damink SWM, et al. Low myoinositol and high glutamine levels in brain are associated with neuropsychological deterioration after induced hyperammonemia. Am J Physiol Gastrointest Liver Physiol 2004;287:G503-9.

54. Kojic J, Robertson PL, Quint DJ, Martin DM, Pang Y, Sundgren PC. Brain glutamine by MRS in a patient with urea cycle disorder and coma. Pediatr Neurol 2005;32:143-6.

55. Swain MS, Blei AT, Butterworth RF, Kraig RP. Intracellular pH rises and astrocytes swell after portacaval anastomosis in rats. Am J Physiol 1991;261:R1491-6.

56. Kanamori K, Ross BD. Glial alkalinization detected in vivo by ${ }^{1} \mathrm{H}-{ }^{15} \mathrm{~N}$ heteronuclear multiple-quantum coherence-transfer NMR in severely hyperammonemic rat. J Neurochem 1997; 68:1209-20.

57. Cooper AJL, McDonald JM, Gelbard AS, Gledhill RF, Duffy TE. The metabolic fate of ${ }^{13} \mathrm{~N}$-labeled ammonia in rat brain. J Biol Chem 1979;254:4982-92.

58. Raichle ME, Larson KB. The significance of the $\mathrm{NH}_{3}-\mathrm{NH}_{4}{ }^{+}$equilibrium on the passage of ${ }^{13} \mathrm{~N}$-ammonia from blood to brain. A new regional residue detection model. Circ Res 1981;48:913-37.

59. Lockwood AH, Yap EW, Wong WH. Cerebral ammonia metabolism in patients with severe liver disease and minimal hepatic encephalopathy. J Cereb Blood Flow Metab 1991;11:337-41.

60. Weigle CG, Koehler RC, Brusilow SW, Traystman RJ. Arterial $\mathrm{pH}$ modulation of regional cerebral blood flow during hyperammonemia in dogs. Am J Physiol Heart Circ Physiol 1990; 259:H34-41.

61. Sørensen M, Keiding S. New findings on cerebral ammonia uptake in HE using functional ${ }^{13} \mathrm{~N}$-ammonia PET. Metab Brain Dis 2007;22:277-84. 
62. Ahl B, Weissenborn K, van den Hoff J, et al. Regional differences in cerebral blood flow and cerebral ammonia metabolism in patients with cirrhosis. Hepatology 2004;40:73-9.

63. Gibson GE, Zimber A, Krook L, Richardson EP, Visek WJ. Brain histology and behavior of mice injected with urease. J Neuropath Exp Neurol 1974;33:201-21.

64. Hindfelt B, Plum F, Duffy TE. Effect of acute ammonia intoxication on cerebral metabolism in rats with portacaval shunts. J Clin Invest 1977;59:386-96.

65. Gjedde A, Lockwood AH, Duffy TE, Plum F. Cerebral blood flow and metabolism in chronically hyperammonemic rats: effect of an acute ammonia challenge. Ann Neurol 1978;3:325-30.

66. Giguère JF, Butterworth RF. Amino acid changes in regions of the CNS in relation to function in experimental portal-systemic encephalopathy. Neurochem Res 1984;9:1309-21.

67. Hawkins RA, Jessy J. Hyperammonaemia does not impair brain function in the absence of glutamine synthesis. Biochem J 1991; 277:697-703.

68. Pasantes-Morales H, Franco R. Astrocyte cellular swelling: Mechanisms and relevance to brain edema, in: The Role of Glia in Neurotoxicity, 2nd Edit. Aschner M, Costa LG, eds. Boca Raton, FL: CRC Press, 2004:173-90.

69. Okada M, Nakao R, Hosoi R, et al. In vivo monitoring of extracellular ${ }^{13} \mathrm{~N}$-glutamine derived from blood-borne ${ }^{13} \mathrm{~N}$-ammonia in rat striatum using microdialysis with radio-LC method. J Neurosci Methods 2009;184:37-41.

70. Cooper AJL, Mora SN, Cruz NF, Gelbard AS. Cerebral ammonia metabolism in hyperammonemic rats. J Neurochem 1985;44:1716-23.

71. Bessman SP, Bessman AN. The cerebral and peripheral uptake of ammonia in liver disease with an hypothesis for the mechanism of hepatic coma. J Clin Invest 1955;34:622-8.

72. Shorey J, McCandless DW, Schenker S. Cerebral $\alpha$-ketoglutarate in ammonia intoxication. Gastroenterology 1967;53:706-11.

73. Cooper AJL, Vergara F, Duffy TE. Cerebral glutamine synthetase. In: Glutamine, glutamate and GABA in the central nervous system. Hertz L, Kvamme E, McGeer EG, Schousboe A, eds. New York: Alan R. Liss, 1983:77-93.

74. Fitzpatrick SM, Hetherington HP, Behar KL, Shulman RG. Effects of acute hyperammonemia on cerebral amino acid metabolism and $\mathrm{pH}_{\mathrm{i}}$ in vivo, measured by ${ }^{1} \mathrm{H}$ and ${ }^{31} \mathrm{P}$ nuclear magnetic resonance. J Neurochem 1989;52:741-9.

75. Hirata T, Koehler RC, Brusilow SW, Traystman RJ. Preservation of cerebral blood flow responses to hypoxia and arterial pressure alterations in hyperammonemic rats. J Cereb Blood Flow Metab 1995;15:835-44.

76. Oldendorf WH, Szabo J. Amino acid assignment to one of three blood-brain barrier amino acid carriers. Am J Physiol 1976;230: $94-8$.

77. Berl S, Takagaki G, Clarke DD, Waelsch H. Carbon dioxide fixation in the brain. J Biol Chem 1962;237:2570-3.

78. Zwingmann C. The anaplerotic flux and ammonia detoxification in hepatic encephalopathy. Metab Brain Dis 2007;22:235-49.

79. Johansen ML, Bak LK, Schousboe A, et al. The metabolic role of isoleucine in detoxification of ammonia in cultured mouse neurons and astrocytes. Neurochem Int 2007;50:1042-51.

80. Howse DC, Duffy TE. Control of the redox state of the pyridine nucleotides in the rat cerebral cortex. Effect of electroshockinduced seizures. J Neurochem 1975;24:935-40.

81. García-Espinosa MA, Wallin R, Hutson SM, Sweatt AJ. Widespread neuronal expression of branched-chain aminotransferase in the CNS: implications for leucine/glutamate metabolism and for signaling by amino acids. J Neurochem 2007;100:1458-68.

82. Hawkins RA, Jessy J, Mans AM, DeJoseph MR. Effects of reducing brain glutamine synthesis on metabolic symptoms of hepatic encephalopathy. J Neurochem 1993;60:1000-6.

83. Kanamori K, Ross BD, Kondrat RW. Rate of glutamate synthesis from leucine in rat brain measured in vivo by ${ }^{15} \mathrm{~N}$ NMR. J Neurochem 1998;70:1304-15.

84. Shen J, Sibson NR, Cline G, Behar KL, Rothman DL, Shulman RG. ${ }^{15} \mathrm{~N}-\mathrm{NMR}$ spectroscopy studies of ammonia transport and glutamine synthesis in the hyperammonemic rat brain. Dev Neurosci 1998;20:434-43.
85. Sibson NR, Mason GF, Shen J, et al. In vivo ${ }^{13} \mathrm{C}$ NMR measurement of neurotransmitter glutamate cycling, anaplerosis and TCA cycle flux in rat brain during $\left[2-{ }^{13} \mathrm{C}\right]$ glucose infusion. J Neurochem 2001;76:975-89.

86. McKhann GM, Tower DB. Ammonia toxicity and cerebral oxidative metabolism. Am J Physiol 1961;200:420-4.

87. Lai JCK, Cooper AJL. Brain $\alpha$-ketoglutarate dehydrogenase complex: kinetic properties, regional distribution and effects of inhibitors. J Neurochem 1986;47:1376-86.

88. Lowry OH, Passonneau JV. Kinetic evidence for multiple binding sites on phosphofructokinase. J Biol Chem 1966;241:2268-79.

89. Fitzpatrick SM, Cooper AJL, Duffy TE. Use of $\beta$-methylene-DLaspartate to assess the role of aspartate aminotransferase in cerebral oxidative metabolism. J Neurochem 1983;41:1370-83.

90. Bjerring PN, Hauerberg J, Frederiksen HJ, et al. Cerebral glutamine concentration and lactate-pyruvate ratio in patients with acute liver failure. Neurocrit Care 2008;9:3-7.

91. Barbiroli B, Gaiani S, Lodi R, et al. Abnormal brain energy metabolism shown by in vivo phosphorus magnetic resonance spectroscopy in patients with chronic liver disease. Brain Res Bull 2002;59:75-82.

92. Weissenborn K, Bokemeyer M, Ahl B, et al. Functional imaging of the brain in patients with liver cirrhosis. Metab Brain Dis 2004;19:269-80.

93. Cavanagh JB, Kyu MH. Type II Alzheimer change experimentally produced in astrocytes in the rat. J Neurol Sci 1971;12:6375.

94. Cole M, Rutherford RB, Smith FO. Experimental ammonia encephalopathy in the primate. Arch Neurol 1972;26:130-6.

95. Zamora AJ, Cavanagh JB, Kyu MH. Ultrastructural responses of the astrocytes to portacaval anastomosis in the rat. J Neurol Sci 1973;18:25-45.

96. Norenberg MD, Lapham LW. The astrocyte response in experimental portal systemic encephalopathy. An electron microscopic study. J Neuropath Exp Neurol 1974;33:422-35.

97. Norenberg MD. A light and electron microscopic study of experimental portal-systemic (ammonia) encephalopathy. Progression and reversal of the disorder. Lab Invest 1977;36:618-27.

98. Voorhies TM, Ehrlich ME, Duffy TE, Petito CK, Plum F. Acute hyperammonemia in the young primate: physiologic and neuropathologic correlates. Pediatr Res 1983;17:970-5.

99. Traber PG, Dal Canto M, Ganger DR, Blei AT. Electron microscopic evaluation of brain edema in rabbits with galactosamineinduced hepatic failure: ultrastructure and integrity of the bloodbrain barrier. Hepatology 1987;7:1272-7.

100. Norenberg MD. Astrocyte responses to CNS injury. J Neuropath Exp Neurol 1994;53:213-20.

101. Willard-Mack CL, Koehler RC, Hirata T, et al. Inhibition of glutamine synthetase reduces ammonia-induced astrocyte swelling in rat. Neuroscience 1996;71:589-99.

102. Martinez A. Electron microscopy in human hepatic encephalopathy. Acta Neuropath 1968;11:82-6.

103. Partin JS, McAdams AJ, Partin JC, Schubert WK, McLaurin RL. Brain ultrastructure in Reye's disease - II. Acute injury and recovery process in three children. J Neuropathol Exp Neurol 1978;37:796-819.

104. Bruton CJ, Corsellis JAN, Russell A. Hereditary hyperammonaemia. Brain 1970;93:423-34.

105. Gregorios JB, Mozes LW, Norenberg L-OB, Norenberg MD. Morphologic effects of ammonia on primary astrocyte cultures: II. Electron microscopic studies. J Neuropath Exp Neurol 1985; 44:404-14.

106. Martinez-Hernandez A, Bell KP, Norenberg MD. Glutamine synthetase: glial localization in brain. Science 1977;195:1356-8.

107. Norenberg MD, Martinez-Hernandez A. Fine structural localization of glutamine synthetase in astrocytes of rat brain. Brain Res 1979;161:303-10.

108. Keiding S, Sørensen M, Bender D, Munk OL, Ott P, Vilstrup H. Brain metabolism of ${ }^{13} \mathrm{~N}$-ammonia during acute hepatic encephalopathy in cirrhosis measured by positron emission tomography. Hepatology 2006;43:42-50.

109. Sørensen M, Keiding S. New findings on cerebral ammonia up- 
take in HE using functional ${ }^{13} \mathrm{~N}$-ammonia PET. Metab Brain Dis 2007;22:277-84.

110. Sørensen M, Munk OL, Keiding S. Backflux of ammonia from brain to blood in human subjects with and without hepatic encephalopathy. Metab Brain Dis 2009;24:237-42.

111. Keiding S, Sørensen M, Munk OL, Bender D. Human ${ }^{13} \mathrm{~N}$-ammonia PET studies: the importance of measuring ${ }^{13} \mathrm{~N}$-ammonia metabolites in blood. Metab Brain Dis 2010;25:49-56.

112. De Graaf AA, Deutz NEP, Bosman DK, Chamuleau RA, de Haan JG, Bovee WM. The use of in vivo proton NMR to study the effects of hyperammonemia in the rat cerebral cortex. NMR Biomed Med 1991;4:31-7.

113. Tsukada Y, Kanamatsu T, Watanabe H, Okamoto K. In vivo investigation of glutamate-glutamine metabolism in hyperammonemic monkey brain using ${ }^{13} \mathrm{C}$-magnetic resonance spectroscopy. Dev Neurosci 1998;20:427-33.

114. Zwingmann C. Nuclear magnetic resonance studies of energy metabolism and glutamine shunt in hepatic encephalopathy and hyperammonemia. J Neurosci Res 2007;85:3429-42.

115. Vergara F, Duffy TE, Plum F. $\alpha$-Ketoglutaramate, a neurotoxic agent in hepatic coma. Trans Assoc Am Physicians 1973;86:255-63.

116. Vergara E, Plum F, Duffy TE. $\alpha$-Ketoglutaramate: increased concentrations in the cerebrospinal fluid of patients in hepatic coma. Science 1974;183:81-3.

117. Duffy TE, Vergara F, Plum F. $\alpha$-Ketoglutaramate in hepatic encephalopathy. Res Publ Assoc Res Nerv Ment Dis 1974;53: $39-52$.

118. Albrecht J, Norenberg MD. Glutamine: a Trojan horse in ammonia neurotoxicity. Hepatology 2006;44:788-94.

119. Murthy CRK, Rama Rao KV, Bai G, Norenberg MD. Ammoniainduced production of free radicals in primary cultures of rat astrocytes. J Neurosci Res 2001;66:282-8.

120. Rama Rao KV, Jayakumar AR, Norenberg MD. Ammonia neurotoxicity: role of the mitochondrial permeability transition. Metab Brain Dis 2003;18:113-27.

121. Jayakumar AR, Rama Rao KV, Schousboe A, Norenberg MD. Glutamine-induced free radical production in cultured astrocytes. Glia 2004;46:296-301.

122. Jayakumar AR, Rao KV, Murthy ChR, Norenberg MD. Glutamine in the mechanism of ammonia-induced astrocyte swelling. Neurochem Int 2006;48:623-8.

123. Jayakumar AR, Rama Rao KV, Tong XY, Norenberg MD. Calcium in the mechanism of ammonia-induced astrocyte swelling. J Neurochem 2009;109(suppl 1):252-7.

124. Norenberg MD, Rao KV, Jayakumar AR. Mechanisms of ammonia-induced astrocyte swelling. Met Brain Dis 2005;20:303-18.

125. Pichilli VBR, Rao KV, Jayakumar AR, Norenberg MD. Inhibition of glutamine transport into mitochondria protects astrocytes from ammonia toxicity. Glia 2007;55:801-9.

126. Kvamme E, Svenneby G, Hertz L, Schousboe A. Properties of phosphate activated glutaminase in astrocytes cultured from mouse brain. Neurochem Res 1982;7:761-70.

127. Olalla L, Gutiérrez A, Jiménez AJ, et al. Expression of the scaffolding PDZ protein glutaminase-interacting protein in mammalian brain. J Neurosci Res 2008;86:281-92.

128. Kvamme E, Nissen-Meyer LS, Roberg BA, Torgner IA. Novel form of phosphate activated glutaminase in cultured astrocytes and human neuroblastoma cells, PAG in brain pathology and localization in the mitochondria. Neurochem Res 2008;33:1341-5.

129. Kanamori K, Ross BD. In vivo activity of glutaminase in the brain of hyperammonaemic rats measured by ${ }^{15} \mathrm{~N}$ nuclear magnetic resonance. Biochem J 1995;305:329-36.

130. Matheson DF, Van Den Berg CJ. Ammonia and brain glutamine: inhibition of glutamine degradation by ammonia. Biochem Soc Trans 1975;3:525-8.

131. Wallace DR, Dawson R Jr. Ammonia regulation of phosphateactivated glutaminase displays regional variation and impairment in the brain of aged rats. Neurochem Res 1992;17:1113-22.

132. Warren KS, Schenker S. Effect of an inhibitor of glutamine synthesis (methionine sulfoximine) on ammonia toxicity and metabolism. J Lab Clin Med 1964;64:442-9.

133. Kosenko E, Kaminsky Y, Solomadin I, et al. Acute ammonia neurotoxicity in vivo involves increase in cytoplasmic protein
P53 without alterations in other markers of apoptosis. J Neurosci Res 2007;85:2491-9.

134. Leung AWC, Halestrap AP. Recent progress in elucidating the molecular mechanism of the mitochondrial permeability transition pore. Biochim Biophys Acta 2008;1777:946-52.

135. Elgudin L, Hall Y, Schubert D. Ammonia induced encephalopathy from valproic acid in a bipolar patient: case report. Int J Psychiatry Med 2003;22:91-6.

136. Mak CM, Siu TS, Lam CW, et al. Complete recovery from acute encephalopathy of late-onset ornithine transcarbamylase deficiency in a 3-year-old boy. J Inher Metab Dis 2007;30:981.

137. Mans AM, Biebuyck JF, Hawkins RA. Ammonia selectively stimulates neutral amino acid transport across blood-brain barrier. Am J Physiol 1983;245:C74-7.

138. Brusilow SW. Inborn errors of ureagenesis. In: Genetic and metabolic disease in pediatrics. Lloyd JK, Scriver CR, eds London: Butterworths, 1985:140-65.

139. Watson AJ, Chambers T, Karp JE, Risch VR, Walker WG, Brusilow SW. Transient idiopathic hyperammonaemia in adults. Lancet $1985 ; 2: 1271-4$.

140. Brusilow SW, Traystman RJ. Hepatic encephalopathy. N Engl J Med 1986;314:786-7.

141. Schenker S, Brady CE III. Pathogenesis of hepatic encephalopathy. In: Hepatic encephalopathies. Conn HO, Bircher J, eds. Bloomington, IL: Med-Ed Press, 1994:442-6.

142. Hindfelt B. The effect of acute ammonia intoxication upon the brain energy state in rats pretreated with methionine D-L-sulphoximine. Scand J Clin Invest 1973;31:289-99.

143. Hindfelt B, Plum F. L-methionine-D,L-sulphoximine and acute ammonia toxicity. J Pharm Pharmac 1975;27:456-8.

144. Takahashi H, Koehler RC, Brusilow SW, Traystman RJ. Glutamine synthetase inhibition prevents cerebral oedema during hyperammonemia. Acta Neurochir 1990;51(suppl):346-7.

145. Takahashi H, Koehler RC, Brusilow SW, Traystman RJ. Inhibition of brain glutamine accumulation prevents cerebral edema in hyperammonemic rats. Am J Physiol 1991;261:H825-9.

146. Sugimoto H, Koehler RC, Wilson DA, Brusilow SW, Traystman RJ. Methionine sulfoximine, a glutamine synthetase inhibitor, attenuates increased extracellular potassium activity during acute hyperammonemia. J Cerebr Blood Flow Metab 1997;17:44-9.

147. Blei AT, Olafsson S, Therrien G, Butterworth RF. Ammoniainduced brain edema and intracranial hypertension in rats after portacaval anastomosis. Hepatology 1994;19:1437-44.

148. Takahashi H, Koehler RC, Hirata T, Brusilow SW, Traystman RJ. Restoration of cerebrovascular $\mathrm{CO}_{2}$ responsivity by glutamine synthesis inhibition in hyperammonemic rats. Circ Res 1992;71: $1220-30$

149. Hirata T, Koehler RC, Kawaguchi T, Brusilow SW, Traystman RJ. Impaired pial arteriolar reactivity to hypercapnia during hyperammonemia depends on glutamine synthesis. Stroke 1996;27: 729-36.

150. Hirata T, Kawaguchi T, Brusilow SW, Traytsman RJ, Koehler RC. Preserved hypocapnic pial arteriolar constriction during hyperammonemia by glutamine synthetase inhibition. Am J Physiol 1999;276:H456-63.

151. Kawaguchi T, Brusilow SW, Traystman RJ, Koehler RC. Glutamine-dependent inhibition of pial arteriolar dilation to acetylcholine with and without hyperammonemia in the rat. Am J Physiol Regul Integr Comp Physiol 2005;288:R1612-9.

152. Tanigami H, Rebel A, Martin LJ, et al. Effect of glutamine synthetase inhibition on astrocyte swelling and altered astroglial protein expression during hyperammonemia in rats. Neuroscience 2005; 131:437-49.

153. Jonung T, Rigotti P, James JH, Brackett K, Fischer JE. Effect of hyperammonemia and methionine sulfoximine on the kinetic parameters of blood-brain transport of leucine and phenylalanine. J Neurochem 1985;45:308-18.

154. Miller JD. Volume and pressure in the craniospinal axis. Clin Neurosurg 1975;22:76-105.

155. Mokri B. The Monro-Kellie hypothesis: applications in CSF volume depletion. Neurology 2001;56:1746-8. 
156. Oberheim NA, Wang X, Goldman S, Nedergaard M. Astrocytic complexity distinguishes the human brain. Trends Neurosci 2006; 29:547-53.

157. Zwingmann C, Chatauret N, Rose C, Leibfritz D, Butterworth RF. Selective alterations of brain osmolytes in acute liver failure: protective effect of mild hypothermia. Brain Res 2004;999:118-23.

158. Maestri NE, McGowan KD, Brusilow SW. Plasma glutamine concentration: a guide in the management of urea cycle disorders. J Pediatr 1992;121:259-61.

159. Tuchman M, Yudkoff M. Blood levels of ammonia and nitrogen scavenging amino acids in patients with inherited hyperammonemia. Mol Genet Metab 1999;66:10-5.

160. Tofteng F, Hauerberg J, Hansen BA, Pedersen CB, Jørgensen L, Larsen FS. Persistent arterial hyperammonemia increases the concentration of glutamine and alanine in the brain and correlates with intracranial pressure in patients with fulminant hepatic failure. J Cereb Blood Flow Metab 2006;26:21-7.

161. Rovira A, Alonso J, Córdoba J. MR imaging findings in hepatic encephalopathy. AJNR Am J Neuroradiol 2008;29:1612-21.

162. Lodi R, Tonon C, Stracciari A, et al. Diffusion MRI shows increased water apparent diffusion coefficient in the brains of cirrhotics. Neurology 2004;62:762-6.

163. Kale RA, Gupta RK, Saraswat VA, et al. Demonstration of interstitial cerebral edema with diffusion tensor MR imaging in type C hepatic encephalopathy. Hepatology 2006;43:698-706.

164. Miese F, Kircheis G, Wittsack HJ, et al. ${ }^{1} \mathrm{H}-\mathrm{MR}$ spectroscopy, magnetization transfer, and diffusion-weighted imaging in alcoholic and nonalcoholic patients with cirrhosis with hepatic encephalopathy. AJNR Am J Neuroradiol 2006;27:1019-26.

165. Behar KL, Rothman DL. In vivo nuclear magnetic resonance studies of glutamate- $\gamma$-aminobutyric acid-glutamine cycling in rodent and human cortex: the central role of glutamine. J Nut 2001;131:2498S-504S.

166. Bröer A, Deitmer JW, Bröer S. Astroglial glutamine transport by system N is upregulated by glutamate. Glia 2004;48:298-310.

167. Schneider HP, Bröer S, Bröer A, Deitmer JW. Heterologous expression of the glutamine transporter SNAT3 in Xenopus oocytes is associated with four modes of uncoupled transport. J Biol Chem 2007;282:3788-98.

168. Bröer S, Schneider HP, Bröer A, Deitmer JW. Mutation of asparagine 76 in the center of glutamine transporter SNAT3 modulates substrate-induced conductances and $\mathrm{Na}^{+}$binding. J Biol Chem 2009;284:25823-31.

169. Kanamori K, Ross BD. Suppression of glial glutamine release to the extracellular fluid studied in vivo by NMR and microdialysis in hyperammonemic rat brain. J Neurochem 2005;94:74-85.

170. Pamiljans V, Krishnaswamy PR, Dumville G, Meister A. Studies on the mechanism of glutamine synthesis; Isolation and properties of the enzyme from sheep brain. Biochemistry 1962;1:153-8.

171. Häussinger D, Schliess F. Pathogenetic mechanisms of hepatic encephalopathy. Gut 2008;57:1156-65.

172. Zwingmann C, Liebfritz D. Ammonia toxicity under hyponatremic conditions in astrocytes: De novo synthesis of amino acids for the osmoregulatory response. Neurochem Int 2005;47:39-50.

173. Zielińska M, Law RO, Albrecht J. Excitotoxic mechanism of cell swelling in rat cortical slices treated acutely with ammonia. Neurochem Int 2003;43:299-303.

174. Sonnewald U, Therrien G, Butterworth RF. Portacaval anastomosis results in altered neuron-astrocytic metabolic trafficking of amino acids. J Neurochem 1996;67:1711-7.

175. Kanamori K, Ross BD, Chung JC, Kuo EL. Severity of hyperammonemic encephalopathy correlates with brain ammonia levels and saturation of glutamine synthetase in vivo. J Neurochem 1996;67:1584-94.

176. Dong G, Benveniste EN. Immune function of astrocytes. Glia 2001;36:180-90.
177. Stravitz RT, Kramer AH, Davern T, et al; the Acute Liver Failure Study Group. Crit Care Med 2007;35:2498-508.

178. Kimelberg HK. Astrocytic swelling in cerebral ischemia as a possible cause of injury and target for therapy. Glia 2005;50:389-97.

179. Kimelberg HK, Macvicar BA, Sontheimer H. Anion channels in astrocytes: biophysics, pharmacology, and function. Glia 2006; 54:747-57.

180. Eisenberg D, Gill HS, Pfluegl GMU, Rotstein SH. Structurefunction relationships of glutamine synthetases. Biochim Biophys Acta 2000;1477:122-45.

181. Laake JH, Slyngstad TA, Haug FM, Ottersen OP. Glutamine from glial cells is essential for the maintenance of the nerve terminal pool of glutamate: immunogold evidence from hippocampal slice cultures. J Neurochem 1995;65:871-81.

182. Zielińska M, Stafiej A, Law RO, Albrecht J. Effects of methionine sulfoximine on the glutamine and glutamate content and cell volume in rat cerebral cortical slices: involvement of mechanisms not related to inhibition of glutamine synthesis. Neurotoxicology 2004;25:443-9.

183. Tews JK, Stone WE. Effects of methionine sulfoximine on levels of free amino acids and related substances in brain. Biochem Pharmacol 1964;13:543-5.

184. Van den Berg CJ, Van den Velden J. The effect of methionine sulphoximine on the incorporation of labelled glucose, acetate, phenylalanine and proline into glutamate and related amino acids in the brains of mice. J Neurochem 1970;17:985-91.

185. Gershoff SN, Elvehjem CA. The relative effect of methionine sulfoximine on different animal species. J Nutr 1951;45:451-8.

186. Sellinger OZ, Azcurra JM, Ohlsson WG. Methionine sulfoximine seizures. VIII. The dissociation of the convulsant and glutamine synthetase inhibitory effects. J Pharmacol Exp Ther 1968;164: 212-22.

187. Folbergrová J. Glycogen and glycogen phosphorylase in the cerebral cortex of mice under the influence of methionine sulphoximine. J Neurochem 1973;20:547-57.

188. Schatz RA, Sellinger OZ. Effect of methionine and methionine sulfoximine on rat brain S-adenosyl methionine levels. J Neurochem 1975;24:63-6.

189. Sellinger OZ, Schatz RA, Porta R, Wilens TE. Brain methylation and epileptogenesis: the case of methionine sulfoximine. Ann Neurol 1984;16(suppl):S115-20.

190. Rowe WB, Meister A. Identification of L-methionine-S-sulfoximine as the convulsant isomer of methionine sulfoximine. Proc Natl Acad Sci USA 1970;66:500-6.

191. Griffith OW, Meister A. Differential inhibition of glutamine and $\gamma$-glutamylcysteine synthetases by $\alpha$-alkyl analogs of methionine sulfoximine that induce convulsions. J Biol Chem 1978;253: 2333-8.

192. Rao SLN, Meister A. In vivo formation of methionine sulfoximine phosphate, a protein-bound metabolite of methionine sulfoximine. Biochemistry 1972;11:1123-7.

193. Cooper AJL, Stephani RA, Meister A. Enzymatic reactions of methionine sulfoximine. Conversion to the corresponding $\alpha$-imino and $\alpha$-keto acids, and to $\alpha$-ketobutyrate and methane sulfinimide. J Biol Chem 1976;251:6674-82.

194. Newell GW, Erickson TC, Gilson WE, Gershoff SN, Elvehjem CA. Studies on human subjects receiving highly ageinized food materials. J Lab Clin Med 1949;34:239-45.

195. Pollack GH. Species specificity of agene toxicity. J Appl Physiol 1949;1:802-6.

196. Blin M, Crusio WE, Hévor T, Cloix J-F. Chronic inhibition of glutamine synthetase is not associated with impairment of learning and memory in mice. Brain Res Bull 2002;57:11-5.

197. Eid T, Ghosh A, Wang Y, et al. Recurrent seizures and brain pathology after inhibition of glutamine synthetase in the hippocampus in rats. Brain 2008;131:2061-70. 